\title{
The Neuroprotective Effects of Insulin-Like Growth Factor 1 via the Hippo/YAP Signaling Pathway is Mediated by the PI3K/AKT Pathway Following Cerebral Ischemia-Reperfusion Injury
}

\section{Pian Gong}

Renmin Hospital of Wuhan University: Wuhan University Renmin Hospital

Yichun Zou

Wuhan University Zhongnan Hospital

\section{Wei Zhang}

Renmin Hospital of Wuhan University: Wuhan University Renmin Hospital

Qi Tian

Renmin Hospital of Wuhan University: Wuhan University Renmin Hospital

\section{Shoumeng Han}

Renmin Hospital of Wuhan University: Wuhan University Renmin Hospital

\section{Zhou Xu}

Renmin Hospital of Wuhan University: Wuhan University Renmin Hospital

\section{Qianxue Chen}

Renmin Hospital of Wuhan University: Wuhan University Renmin Hospital

mingchang li ( $\sim$ Mingcli@whu.edu.cn )

Wuhan University Renmin Hospital https://orcid.org/0000-0003-4019-8886

\section{Original Article}

Keywords: Insulin-like growth factor 1, Hippo/YAP signaling pathway, PI3K/AKT signaling pathway, ischemic stroke

Posted Date: February 5th, 2021

DOl: https://doi.org/10.21203/rs.3.rs-187237/v1

License: (9) (1) This work is licensed under a Creative Commons Attribution 4.0 International License. Read Full License 


\section{Abstract}

Insulin-like growth factor 1 (IGF-1) exhibits neuroprotective properties, such as vasodilatory and antiinflammatory effects following ischemic stroke. However, the specific molecular mechanisms of action of IGF-1 following ischemic stroke remain elusive. We wanted to explore whether IGF-1 regulates Hippo/YAP signaling pathway, potentially via activation of the PI3K/AKT signaling pathway to exert its neuroprotective effects following ischemic stroke. In the in vitro study, we used oxygen-glucose deprivation to injure cultured PC12 and SH-5YSY cells, and cortical primary neurons. Cell viability was measured using CCK-8 assay. For the in vivo analyses, Sprague-Dawley rats were subjected to middle cerebral artery occlusion; neurological function was assessed using the neurological deficit score; infarct volume was measured using triphenyltetrazolium chloride staining, and neuronal death and apoptosis was evaluated by TUNEL staining, H\&E staining and Nissl staining. Western blot was used to measure the levels of YAP/TAZ, PI3K and phosphorylated AKT (p-AKT) both in vitro and in vivo. We found that IGF-1 induced activation of YAP/TAZ, which resulted in improved cell viability in vitro, and decreased neurological deficits, neuronal death and apoptosis, and cerebral infarct volume in vivo. Notably, the neuroprotective effects of IGF-1 were reversed by an inhibitor of the PI3K/AKT signaling pathway, LY294002, which not only reduced expressions of PI3K and p-AKT, but also down-regulated expression of YAP/TAZ, leading to aggravation of neurological dysfunction. These findings indicate that neuroprotective effect of IGF-1 is partly realized by up-regulation of YAP/TAZ, which is mediated by activation of the PI3K/AKT signaling pathway following cerebral ischemic stroke.

\section{Highlights}

- IGF-1 exerts neuroprotective effects following ischemia-reperfusion injury.

- IGF-1 activates the PI3K/AKT signaling pathway following ischemia-reperfusion injury.

- IGF-1 regulates Hippo/YAP signaling pathway through the activation of PI3K/AKT signaling pathway to exert its protective effects following ischemia-reperfusion injury.

\section{Introduction}

Insulin-like growth factor 1 (IGF-1) is a single-chain polypeptide with 70 amino acids with a primary amino acid sequence and tertiary structure that is similar to insulin [1]. IGF-1 is primarily produced in the liver in response to growth hormone, and exerts multiple metabolic actions and induces cell proliferation and differentiation [2]. Several studies have shown that IGF-1 plays an important role in brain development and function by regulating neuronal cell proliferation, differentiation and synaptogenesis through unique membrane receptors that are abundantly expressed in neurocytes [3]. In addition, IGF-1 is expressed at low levels in the olfactory bulb, cerebral cortex, hypothalamus, brainstem, and cerebellum, and has a neuroprotective function in adults [4]. Previous reports have suggested that IGF-1 exerts protective actions in many types of central nervous system (CNS) diseases, especially in ischemic stroke [5-7]. Ischemic stroke accounts for approximately $87 \%$ of cases of stroke, which is the second most 
common cause of mortality and the leading cause of adult disability worldwide [8]. Thrombolytic therapy with tissue plasminogen activator (tPA) or mechanical thrombectomy induces reperfusion that can be life-saving for patients with ischemic stroke. However, reperfusion not only brings restoration of blood flow to the brain, but also to the ischemia-reperfusion (I/R) injury, which worsens the prognosis of patients with cerebral ischemic stroke. Thus, it is important to identify the underlying mechanisms of $I / R$ injury and identify new methods to counteract l/R injury.

Some reports have suggested that IGF-1 plays a major role in the long-term recovery process following ischemic stroke or $\mathrm{I} / \mathrm{R}$ injury by enhancing regeneration via stimulation of the proliferation and differentiation of neurons, oligodendrocyte progenitors and myelin expression [9]. IGF-1 has also been found to stimulate neuroplasticity, which is vital for the brain's survival following stroke [10-12]. Among patients with stroke, plasma IGF-1 levels have been reported to be lower in individuals with a relatively large infarct [13], and stroke-associated mortality was lower in patients with higher IGF-1 levels [14]. Furthermore, higher IGF-1 levels have been associated with improved stroke outcomes [15].

The neuroprotection conferred by IGF-1 refers to the mechanisms and strategies of IGF-1 that limit the extent of neuronal injury, which decreases mortality and improves prognosis for patients with ischemic stroke. Treatment with IGF-1 before or after ischemic insult in animal models has been found to significantly decrease both lesion volume and apoptosis in injured areas [16]. The underlying mechanism of this protective effect of IGF-1 might be its action against excitotoxicity, oxidative stress [17], and apoptosis [18]; however, the molecular mechanisms have not yet been thoroughly explored.

The Hippo/YAP kinase cascade is a critical regulator of organ size, tissue regeneration and tumor suppression [19]. The key proteins in the Hippo/YAP kinase cascade are YAP and TAZ, which were found to have a neuroprotective effect against I/R injury in our previous study [19]. Recent research has suggested that IGF-1 activates phosphatidyl inositol-3-kinase (PI3K)-phosphoinositide-dependent kinase 1 (PDK1) - protein kinase B (AKT) to inhibit the Hippo/YAP signaling pathway or increase YAP levels, which results in cell proliferation and tissue growth in both Drosophila and mammals [20]. However, it remains unclear whether the Hippo/YAP pathway and PI3K/AKT signaling pathway are involved in the mechanism of IGF-1 in ischemic stroke and I/R injury.

In the present study, we examined whether IGF-1 exerts its neuroprotective actions following ischemic stroke via the Hippo/YAP signaling pathway, and whether this is mediated by the PI3K/AKT signaling pathway.

\section{Materials And Methods Cells and cell culture}

PC12 cells were purchased from the Kunming Institute of Zoology (Kunming, China). To transform PC12 cells into neuron-like cells, the cells were differentiated with $50 \mathrm{ng} / \mathrm{mL}$ nerve growth factor (NGF, 450-01, PeproTech, Rocky Hill, USA) for 2 days before the experiments. These cells were seeded into flasks 
(density of $1 \times 10^{4}$ cells $/ \mathrm{mL}$ ) in Dulbecco's minimal Eagle medium (DMEM, 8119174, Gibco, NY, USA) supplemented with $10 \%$ (v/v) fetal bovine serum (FBS, 1989478, Gibco, Penrose, Auckland), $100 \mathrm{U} / \mathrm{mL}$ penicillin and $100 \mu \mathrm{g} / \mathrm{mL}$ streptomycin (Genom, GNM15140, Hangzhou, China). Cells were cultured at $37^{\circ} \mathrm{C}$ in a humidified incubator with $5 \% \mathrm{CO}_{2}$.

SH-SY5Y cells were purchased from Procell (CL-0208, Wuhan, China). SH-SY5Y cells were maintained in Dulbecco's modified Eagle medium: nutrient mixture F-12 (DMEM/F-12, Meilun Biotechnology, MAO214Mar-19E (R), Dalian, China) in flasks (density of $1 \times 10^{4}$ cells $/ \mathrm{mL}$ ) supplemented with $10 \% \mathrm{FBS}, 100$ $\mathrm{U} / \mathrm{mL}$ penicillin and $100 \mu \mathrm{g} / \mathrm{mL}$ streptomycin at $37^{\circ} \mathrm{C}$ in a humidified incubator with $5 \% \mathrm{CO}_{2}$ for 7 days before the experiments [21, 22].

Cortical primary neurons were isolated from one-day-old Sprague-Dawley rats according to a previously published protocol with some modifications [23]. Briefly, the newborn rats were sacrificed and their brains were collected. Cortices were isolated, removed and placed in a Petri dish. Meninges and blood vessels surrounding the brain tissue were removed under a microscope. The left hemisphere cortices were quickly moved to a $15 \mathrm{~mL}$ centrifuge tube filled with $5 \mathrm{~mL}$ Neurobasal Medium (2073081, Gibco, NY, USA) containing 2\% B27 (17504044, Thermo Fisher Scientific, MA, USA) and 0.5 $\mu \mathrm{M} \mathrm{L-glutamine} \mathrm{(Genom,}$ GNM21051, Hangzhou, China). Samples were minced and homogenized and the solution was left to stand for $1 \mathrm{~min}$. The supernatant was discarded, and $2 \mathrm{~mL}$ Neurobasal Medium with $0.5 \%$ FBS, $2 \%$ B27 and $0.5 \mu \mathrm{M} \mathrm{L-glutamine} \mathrm{was} \mathrm{added} \mathrm{to} \mathrm{the} \mathrm{centrifuge} \mathrm{tube.} \mathrm{The} \mathrm{solution} \mathrm{with} \mathrm{brain} \mathrm{tissue} \mathrm{was}$ mechanically dissociated into a single cell suspension by mixing with a plastic straw 20 times. After funnel filtration, the single cell suspension with the highest purity was cultured at $37^{\circ} \mathrm{C}$ in a humidified incubator with $5 \% \mathrm{CO}_{2}$. Primary neurons were cultured for 8 days before experiments.

\section{Oxygen And Glucose Deprivation (ogd) Model}

The culture medium was changed to glucose-free DMEM (11966025, Gibco, NY, USA) without FBS and cells were placed in an anaerobic, temperature-controlled $\left(37^{\circ} \mathrm{C}\right)$ chamber flushed with $5 \% \mathrm{CO}_{2}$ and $95 \%$ $\mathrm{N}_{2}(\mathrm{v} / \mathrm{v})$ for different durations according to the cell type and treatment (12 h for PC12 and SH-SY5Y cells, and $6 \mathrm{~h}$ for primary neurons).

Then, PC12 and SH-SY5Y cells were removed from the incubator, cultured with the normal DMEM (8119174, Gibco, NY, USA) containing 10\% FBS (1989478, Gibco, Penrose, Auckland) and $1 \mathrm{~g} / \mathrm{L}$ glucose, and returned to the incubator under normoxic conditions $\left(37^{\circ} \mathrm{C}, 5 \% \mathrm{CO}_{2}\right)$ for $24 \mathrm{~h}$, resulting in reperfusion. The primary neurons were cultured with Neurobasal Medium containing 0.5\% FBS (1989478, Gibco, Penrose, Auckland), $2 \%$ B27 and $0.5 \mu \mathrm{M} \mathrm{L-glutamine} \mathrm{in} \mathrm{an} \mathrm{incubator} \mathrm{under} \mathrm{normoxic} \mathrm{conditions}\left(37^{\circ} \mathrm{C}, 5 \%\right.$ CO2) for $24 \mathrm{~h}$. The cells were collected for experiments after reperfusion.

Experimental groups and drug treatmentin vitro 
Both IGF-1 (recombinant human IGF-1, Intergen, NY, USA) and LY294002 (Sigma-Aldrich, St. Louis, MO, USA) were dissolved in dimethyl sulfoxide (DMSO). First, we wanted to explore the effects of different IGF-1 concentrations in three kinds of cells. The different concentrations administered in different cells were as follows: $5,10,50,100$, and $200 \mathrm{ng} / \mathrm{mL}$ [24] for both PC12 and SH-SY5Y cells that underwent OGD for $12 \mathrm{~h}$, and $5,15,25$, and $50 \mathrm{ng} / \mathrm{mL}$ [25] for primary neurons that underwent OGD for $6 \mathrm{~h}$. Cell Counting Kit-8 (CCK-8) assay was used to assess cell viability of the three kinds of cells at different concentrations of IGF-1 to determine the optimal IGF-1 concentrations in PC12 cells, SH-SY5Y cells and primary neurons.

Then, we defined several groups to detect the effects of IGF-1 on cells that underwent OGD. In the Normoxia group, cells $\left(1 \times 10^{6}\right.$ cells $\left./ \mathrm{mL}\right)$ were cultured under normal conditions for $24 \mathrm{~h}$ without OGD. In the OGD group, PC12 and SH-SY5Y cells $\left(1 \times 10^{6}\right.$ cells $\left./ \mathrm{mL}\right)$ underwent OGD for $12 \mathrm{~h}$ and primary neurons $\left(1 \times 10^{6}\right.$ cells $\left./ \mathrm{mL}\right)$ underwent OGD for $6 \mathrm{~h}$. In the OGD + DMSO group, PC12 and SH-SY5Y cells were administered with DMSO and simultaneously underwent OGD for $12 \mathrm{~h}$, and primary neurons were administered with DMSO and simultaneously underwent OGD for $6 \mathrm{~h}$. In the OGD + IGF-1 group, PC12 and SH-SY5Y cells were administered with IGF-1 $(100 \mathrm{ng} / \mathrm{mL})$ and simultaneously underwent OGD for $12 \mathrm{~h}$, and primary neurons were administered with IGF-1 $(25 \mathrm{ng} / \mathrm{mL})$ and simultaneously underwent OGD for 6 h. In the OGD + IGF-1 + LY294002 group, PC12 and SH-SY5Y cells were administered with both IGF-1 (100 $\mathrm{ng} / \mathrm{mL}$ ) and LY294002 (10 $\mu \mathrm{M}$ for PC12 cells [26] and $30 \mu \mathrm{M}$ for SH-SY5Y cells [21] ) and simultaneously underwent OGD for $12 \mathrm{~h}$, and primary neurons were administered with IGF- $1(25 \mathrm{ng} / \mathrm{mL})$ and LY294002 $(10 \mu \mathrm{M})[27]$ and simultaneously underwent OGD for $6 \mathrm{~h}$.

\section{CCK-8 assay}

Cells were seeded at a suitable density in 96-well plates (10000 cells/well) and cell viability was measured using a CCK-8 assay (Meilun Biotechnology, Dalian, China) according to the manufacturer's instructions. CCK-8 solution was added to the culture medium, and cells were incubated for $4 \mathrm{~h}$ at $37^{\circ} \mathrm{C}$ in a humidified incubator with $5 \% \mathrm{CO}_{2}$. The absorbance was measured at $450 \mathrm{~nm}$ using a Microplate Reader (Bio-Rad, Hercules, CA, USA).

\section{Animals}

Adult male Sprague-Dawley rats, weighing 240-270 g, were purchased from the Wuhan University Center for Animal Experiments and housed under controlled conditions ( 3 rats per cage, $22-25^{\circ} \mathrm{C}, 50-60 \%$ relative humidity, and $12 \mathrm{~h}$ light/dark cycle) with free access to water and food. The rats were allowed to adjust to the environment for 3 days before the surgery, and their weights were properly controlled. The protocols used were approved by the Institutional Animal Care and Use Committee of Wuhan University. All procedures adhered to the regulations specified by the National Institutes of Health Guide for the Care and Use of Laboratory Animals. All efforts were made to minimize the number of rats used, as well as their suffering and mortality. The investigators were blinded to the treatment status of the animals during all surgical procedures.

\section{Middle cerebral artery occlusion (MCAO) model}


We established the MCAO model as described in our previous studies $[23,28]$. The rats were anaesthetized with $4 \%$ isoflurane followed by an incision approximately $15 \mathrm{~mm}$ in the middle of the neck. A silicone-coated nylon monofilament (SunbioBiotech, Beijing, China) with a diameter of $0.45 \mathrm{~mm}$ was

gently inserted via a bevel incision into the left external carotid artery (ECA) to a point approximately 18.5 $\pm 0.5 \mathrm{~mm}$ away from the bifurcation of the left carotid artery (CCA), where resistance was felt. The monofilament was fixed by suture and the connective tissue and skin were stitched up. After 90 min, the monofilament was removed for reperfusion injury and the external carotid artery was ligated. Rats that underwent the surgery were housed at a constant $25^{\circ} \mathrm{C}$ (temperature was maintained by an electric heater) with free access to water and food. The brains were harvested for experiments $24 \mathrm{~h}$ after surgery.

\section{Experimental groups and drug treatmentin vivo}

Both IGF-1 (recombinant human IGF-1, Intergen, NY, USA) and LY294002 (Sigma-Aldrich, St. Louis, MO, USA) were dissolved in DMSO. In the Sham group, rats underwent $4 \%$ isoflurane anesthesia, identical surgery and lateral ventricle injection except for the insertion of monofilament, in that it was withdrawn immediately. In the MCAO group, rats underwent I/R injury. In the MCAO + DMSO group, rats were given DMSO $(5 \mu \mathrm{L}) 30$ min before the MCAO surgery through a lateral ventricle injection (using the bregma as the anatomical reference point: anteroposterior, $0.8 \mathrm{~mm}$; lateral, $1.5 \mathrm{~mm}$; depth, $3.5 \mathrm{~mm}$ ) at the rate of 1.0 $\mu \mathrm{L} / \mathrm{min}$ by $10 \mu \mathrm{L}$ microsyringe. In the MCAO + IGF-1 group, rats were given IGF-1 (0.1 mg, $5 \mu \mathrm{L})$ [29] 30 min before the MCAO surgery through a lateral ventricle injection at the rate of $1.0 \mu \mathrm{L} / \mathrm{min}$. In the MCAO + IGF-1 + LY294002 group, rats were given $5 \mu$ L DMSO solution, in which IGF-1 (0.1 mg) and LY294002 $(50 \mathrm{mM})$ [30] were dissolved $30 \mathrm{~min}$ before the MCAO surgery, through a lateral ventricle injection at the rate of $1.0 \mu \mathrm{L} / \mathrm{min}$.

\section{Neurological deficit score}

The neurological examination was performed $24 \mathrm{~h}$ after MCAO surgery using a previously published modified neurologic scoring system [31,32] as follows: 0 , no deficits; 1 , difficulty in fully extending the contralateral forelimb; 2 , inability to extend the contralateral forelimb; 3 , mild circling toward the contralateral side; 4 , severe circling; and 5 , falling onto the contralateral side. A higher score indicates a more critical I/R injury.

\section{Triphenyltetrazolium chloride (TTC) staining}

The cerebral infarct volume was evaluated by $2 \%$ 2, 3, 5-triphenyltetrazolium chloride (TTC, Sigma, St. Louis, MO, USA; dissolved in phosphate buffer saline) $[33,34]$ staining. Rats were anesthetized by $5 \%$ isoflurane $24 \mathrm{~h}$ after the MCAO surgery, and brains were collected quickly. A $2 \mathrm{~mm}$ section of the frontal pole was discarded, and the remaining brain tissue was sliced into eight coronal sections approximately $2 \mathrm{~mm}$ in thickness using a sharp blade. Each slice was submerged into $2 \%$ TTC solution and stained at $37^{\circ} \mathrm{C}$ for $30 \mathrm{~min}$ in the dark. Finally, $4 \%$ paraformaldehyde was poured over to immerse the brain sections overnight in a fridge maintained at $4^{\circ} \mathrm{C}$. 
Normal tissue was stained bright red, while the infarct area remained pale gray. The stained tissues were imaged and analyzed using Image $\mathrm{J}$ software (National Institutes of Health, Bethesda, MD, USA). The infarct volume percentage was calculated as the infarct area of the ipsilateral hemisphere/total area of ipsilateral hemisphere $\times 100 \%$ [28].

\section{TdT-mediated dUTP Nick-End Labeling (TUNEL) assay, immunofluorescence, Hematoxylin-eosin (H\&E) staining and Nissl staining}

As soon as rats had been sacrificed, the brains were removed and quickly frozen at $-80^{\circ} \mathrm{C}$. Brains were fixed by $4 \%$ paraformaldehyde for $24 \mathrm{~h}$, and then dehydrated, embedded in transparent, dipped paraffin wax, and sliced ( $10 \mu$ m-thick coronal sections). Then, the TUNEL assay was applied according to the manufacturer's instructions. Three stained sections were collected from the core ischemic area of every rat. Five different fields in each section were randomly selected for analysis under a microscope at $400 \times$ magnification. The percentage of TUNEL-positive nuclei in the region was calculated to evaluate apoptosis.

Immunofluorescence was performed as described in our previous studies [19, 35]. The paraffin sections were incubated with the following primary antibodies: rabbit polyclonal anti- GFAP antibody (1:200, 17490-1-AP, Santa Cruz); rabbit polyclonal anti- IBA-1 antibody (1:200, 019-19741, Wako); mouse monoclonal anti- IGF-1 antibody (1:200, NBP2-34361, Novus Biologicals); and rabbit polyclonal antiMAP2 antibody (1:200, 17490-1-AP, Santa Cruz,). Images were collected by fluorescence microscopy at $200 \times$ or $400 \times$ magnification.

For H\&E and Nissl staining, the paraffin sections were stained with H\&E and toluidine blue (Nissl staining) reagent at room temperature for $10 \mathrm{~min}$. An observer who was blinded to the experiment counted the number of normal neurons and viable neurons in the three different fields. Pathological changes were observed using a light microscope at $40 \times$ magnification.

\section{Western blot}

Cells were lysed with RIPA lysis buffer on ice for $30 \mathrm{~min}$. Lysates were centrifuged at $4^{\circ} \mathrm{C}$ and $12000 \times \mathrm{g}$ for $15 \mathrm{~min}$ and supernatants were collected. Brain tissue was cut into pieces with small scissors and washed several times with $0.9 \%$ saline at $4^{\circ} \mathrm{C}$. The brain tissue was grinded into pulp with a grinding rod, and the pulp was transferred to a $10 \mathrm{~mL}$ centrifugal tube. Tissue RIPA lysis buffer and Phenylmethanesulfonyl Fluoride (PMSF) were added and the solution was lysed on ice for $30 \mathrm{~min}$. The solution was blown repeatedly with a micro pipette to ensure that samples were completely lysed. Lysates were centrifuged at $4^{\circ} \mathrm{C}$ and $14000 \times \mathrm{g}$ for $20 \mathrm{~min}$ and the supernatants were collected.

To each protein sample, $5 \times$ sample buffer was added at a ratio of $4: 1$. Samples were heated at $100^{\circ} \mathrm{C}$ for $10 \mathrm{~min}$ and $\beta$-mercaptoethanol was added. 
Western blot was performed as described in our previous work [36]. Briefly, after SDS-PAGE, the proteins were transferred to a PVDF membrane (Millipore, Billerica, MA, USA). Western blot analysis was performed with the following antibodies: rabbit polyclonal anti-GAPDH antibody (1:2000, 10494-1-AP, Santa Cruz Biotechnology, Dallas, TX, USA); rabbit polyclonal anti- $\beta$-actin antibody (1:2000, ab8227, Abcam, Cambridge, MA, USA); rabbit polyclonal anti-PI3K antibody (1:2000, ab191606, Abcam, Cambridge, MA, USA); rabbit polyclonal anti-p-AKT antibody (1:2000 ab8805, Abcam, Cambridge, MA, USA); rabbit polyclonal anti-YAP antibody (1:1000, ab76252, Abcam, Cambridge, MA, USA); rabbit monoclonal anti-TAZ antibody (1:1000, ab84927, Abcam, Cambridge, MA, USA); and rabbit polyclonal anti-Caspase 3 antibody (1:1000, ab13847, Abcam, Cambridge, MA, USA).

The membrane was then incubated with a secondary goat anti-rabbit antibody (1:1000, ab6721, Abcam, Cambridge, MA, USA) for $2 \mathrm{~h}$ at room temperature. The protein electrophoresis bands were imaged using an Odyssey infrared scanner (LICOR Bioscience, Lincoln, NE, USA) and analyzed using Image J software.

\section{Statistical analysis}

The data were analyzed with the SPSS for Windows 20.0 software package and GraphPad Prism Version 6.0 software (GraphPad Software Inc., La Jolla, CA, USA) and were expressed as means \pm SD. The images were analyzed by Image $\mathrm{J}$ software. Differences among groups were determined by performing a oneway ANOVA, followed by Turkey posthoc tests. Two-tailed t tests were used for comparisons between two groups. A two-tailed $p$ value $<0.05$ was considered statistically significant.

\section{Results}

\section{IGF-1 improved cell viability in the OGD model}

As mentioned earlier, PC12 and SH-SY5Y cells underwent OGD for $12 \mathrm{~h}$ and primary neurons underwent OGD for $6 \mathrm{~h}$. We first explored the optimal concentrations of IGF-1 in the OGD models for PC12 cells, SHSY5Y cells, and primary neurons, and CCK-8 assay revealed that IGF-1 had a dose-dependent effect on the activity of PC12 cells (Fig. 1A), SH-SY5Y cells (Fig. 1B) and primary neurons (Fig. 1C). CCK-8 analysis suggested that the IGF-1 concentration of $100 \mathrm{ng} / \mathrm{mL}$ resulted in increased cell viability in $\mathrm{PC} 12$ and SHSY $5 Y$ cells, and an IGF-1 concentration of $25 \mathrm{ng} / \mathrm{mL}$ resulted in increased cell viability in primary neurons. Thus, the concentration of $100 \mathrm{ng} / \mathrm{mL}$ was administered in both PC12 and SH-SY5Y cells, and $25 \mathrm{ng} / \mathrm{mL}$ was administered in the primary neurons in the following OGD experiments.

\section{IGF-1 affected the Hippo/YAP signaling pathway, potentially via the PI3K/AKT cascade}

Considering the potent neuroprotective and regenerative effects of IGF-1 and our previous findings that YAP/TAZ exerted a neuroprotective effect following I/R injury, we examined whether administration of exogenous IGF-1 increased YAP/TAZ expression. As predicted, IGF-1 increased the levels of YAP and TAZ in PC12 cells, SH-SY5Y cells, and primary neurons that underwent OGD (Fig. 2A, B, C, D, E, H, I, L and M). 
Moreover, PI3K and p-AKT expressions increased following IGF-1 treatment (Fig. 2A, B, C, F, G, J, K, N and O), which suggests that IGF-1 conferred neuroprotective effects in ischemic stroke by interfering with the PI3K/AKT signaling pathway. Interestingly, the inhibitor of the PI3K/AKT cascade, LY294002, not only repressed the expression of PI3K, but also reversed the IGF-1-induced increase in YAP (Fig. 3A, B, C, D, E, $\mathrm{G}, \mathrm{H}, \mathrm{J}$ and $\mathrm{K}$ ), which further indicates that the PI3K/AKT cascade facilitates the increment of YAP/TAZ and even the neuroprotective effect of the Hippo/YAP signaling pathway in I/R injury. Furthermore, to investigate the effect of IGF-1 on apoptosis, we measured the expression of Caspase 3, and the result showed that IGF-1 decreased the expression of Caspase 3, which suggested that IGF-1 attenuated the apoptosis induced by OGD (Fig. 3A, B, C, F, I and L). However, the protective effects of IGF-1 were reversed by LY294002, which not only implies that inhibition of the PI3K/AKT signaling pathway aggravates neural apoptosis in the OGD model, but also shows that one mechanism underlying the neuroprotective effects of IGF-1 could be activation of the PI3K/AKT signaling pathway.

IGF-1 expression in astrocytes and microglia was increased in response to ischemic stroke.

To determine how IGF-1 is expressed in ischemic stroke in vivo, we implemented the double immunofluorescence staining method. To assess the quantity changes and locations of astrocytes and microglia, as well as the expression of IGF-1 in infarct cortices, we labeled IGF-1, GFAP (which represents astrocytes; Fig. 4A), and IBA-1 (which represents microglia; Fig. 4B). Moreover, to explore the survival of neurons in different groups, MAP2 was used to label neurons (Fig. 5).

$\mathrm{GFAP}^{+}$and $\mathrm{IBA}-1^{+}$cell counts were elevated in the MCAO groups relative to the Sham group, which revealed apparent neuroinflammation. IGF-1 was expressed in astrocytes and microglia, and the IGF-1 level was higher in the MCAO group than in the Sham group (Fig. 4A and B).

Compared to the MCAO group and MCAO + DMSO group, MAP2 ${ }^{+}$cell numbers in the MCAO + IGF- 1 were relatively increased (Fig. 5). However, LY294002 reversed the effects of IGF-1 on neurons to some extent (Fig. 5), which not only indicates that the neuroprotective effect of the PI3K/AKT signaling pathway was inhibited by LY294002, but also shows that the protective effect of IGF-1 might be mediated by the $\mathrm{PI3K} / \mathrm{AKT}$ signaling pathway in ischemic stroke.

\section{Both IGF-1 and the PI3K/AKT signaling pathway mediated neuroprotection}

A neurological deficit score system was applied to evaluate the neurological functional recovery of rats. As illustrated in Fig. 6A, the neurological deficit score of the MCAO + IGF-1 group increased compared to the MCAO group and MCAO + DMSO group (Fig. 6A). However, LY294002 reversed the improved neurological function induced by IGF-1 (Fig. 6A).

To further test whether IGF-1 conferred neuroprotection against ischemic stroke, we measured infarct volume of rats in different groups by TTC staining (Fig. 6B and C). IGF-1 clearly decreased the infarct volume. To investigate whether this IGF-1-induced decrease in infarct volume was mediated by the 
PI3K/AKT signaling pathway, we administered LY294002 together with IGF-1; LY294002 reversed the IGF1-induced decrease in infarct volume (Fig. 6B and C). This indicates that IGF-1 exerted protective effects by activating the PI3K/AKT signaling pathway.

\section{Both IGF-1 and the PI3K/AKT signaling pathway repressed apoptosis}

According to the above findings, we hypothesized that IGF-1 can inhibit neuronal apoptosis in ischemic stroke. We measured neuronal apoptosis using TUNEL staining $24 \mathrm{~h}$ after the MCAO surgery. IGF-1 decreased the number of apoptotic cells in the core infarct area (Fig. 7). However, the beneficial effects of IGF-1 were reversed by LY294002 (Fig. 7A and B). As expected, inhibition of the PI3K/AKT signaling pathway aggravated apoptosis (Fig. 7A and B). Thus, both IGF-1 and the PI3K/AKT signaling pathway activation might contribute to neuroprotection in ischemic stroke and PI3K/AKT pathway activation could be a neuroprotective mechanism of IGF-1 in ischemic stroke.

\section{Both IGF-1 and the PI3K/AKT signaling pathway protected neurons against ischemic stroke}

H\&E staining showed that normal neurons in the Sham group exhibited regular round and bright blue nuclei, while in the MCAO groups, injured neurons showed apparent apoptotic features, including nuclear chromatin pyknosis, side scatter, and fracture. IGF-1 reduced the number of dead neurons in rats that underwent MCAO surgery (Fig. 8A and C). However, LY294002 reversed the protective effects of IGF-1 on neurons (Fig. 8A and C). Nissl staining revealed normal neurons without cerebral cortex edema in the Sham group, and apparent neuronal necrosis and irregularly arranged Nissl substance in the MCAO groups. Less neuronal necrosis and irregularly arranged Nissl substance were observed in the MCAO + IGF-1 group (Fig. 8B and D). Similarly, the effects of IGF-1 were reversed by LY294002 (Fig. 8B and D).

IGF-1 regulated the Hippo/YAP signaling pathway in vivo, potentially via the PI3K/AKT cascade

To further investigate whether IGF-1 regulated YAP/TAZ expression in vivo, we performed western blot of the brain tissue. As shown in our previous study, the levels of YAP and TAZ in MCAO-treated rats were clearly lower than those seen in the Sham-operated rats (Fig. 9A, B, C and G). IGF-1 increased the expressions of both PI3K and p-AKT, which is suggestive of the proliferative effect of IGF-1 in ischemic stroke (Fig. 9A, B, D and F). LY294002 not only decreased the levels of PI3K and p-Akt, but also decreased the levels of YAP and TAZ, which suggests that the PI3K/AKT signaling pathway might regulate the Hippo/YAP pathway to relieve I/R injury. YAP/TAZ expression in the MCAO + IGF-1 + LY294002 group was lower than in the MCAO + IGF-1 group, which suggests that IGF-1 activated the PI3K/AKT signaling pathway to elevate the level of YAP/TAZ, resulting in protection against I/R injury. Moreover, we also tested the expression of Caspase 3 in vivo (Fig. 9A and E). Compared to the MCAO group and MCAO + DMSO group, IGF-1 decreased the expression of Caspase 3 in the MCAO + IGF-1 group (Fig. 9A and E). Furthermore, the anti-apoptotic effect of IGF-1 was reversed by LY294002. 


\section{Discussion}

In this study, we first wanted to determine whether IGF-1 protected neurons against I/R injury. We found that appropriate concentrations of IGF-1 exerted its neuroprotective effect in three kinds of neural cells that underwent OGD, and that IGF-1 increased cell viability alongside modified levels of PI3K/p-AKT and YAP/TAZ. Thus, we then explored whether the mechanism underlying the neuroprotective effect of IGF-1 was related to the PI3K/AKT and Hippo/YAP signaling pathways following ischemic stroke. IGF-1 induced activation of YAP/TAZ, which resulted in increased cell viability in vitro, and decreased neurological deficits, neural death and apoptosis, and cerebral infarct volume in vivo. In the experiments in which both IGF-1 and LY294002 were administered, IGF-1-induced YAP/TAZ activation was eliminated by LY294002 to some extent along with decreased expression levels of PI3K and p-AKT and relatively serious brain damage. This indicates that the neuroprotective effect of IGF-1 might be partly mediated by up-regulation of YAP/TAZ through activation of the PI3K/AKT signaling pathway in cerebral I/R injury. Furthermore, we found that GFAP ${ }^{+}$and IBA- $1^{+}$cell counts were elevated in brains with I/R injury, which is indicative of the reactive proliferation of astrocytes and microglia and apparent neuroinflammation observed following ischemic stroke. We also found that IGF-1 was expressed in astrocytes and microglia, and the IGF-1 expression level was increased along with the proliferation of astrocytes and microglia. $\mathrm{MAP}^{+}$cells were decreased in rats with I/R injury and were up-regulated by IGF-1, which indicates that neuronal damage can be alleviated by IGF-1.

Consistent with our previous research [19], the current results showed that the Hippo/YAP signaling pathway was involved in the pathophysiological process following ischemic stroke. We also found that regulation of YAP/TAZ reduced I/R injury, and that YAP/TAZ expression was increased by IGF-1. These results reveal a new neuroprotective mechanism of IGF-1 following ischemic stroke. Our study is the first to suggest the presence of an IGF-1-PI3K/AKT-Hippo/YAP cascade following ischemic stroke of rats and this cascade may play an important role in the pathogenesis and prognosis of ischemic stroke, providing a new therapeutic target of cerebral ischemic stroke.

The Hippo/YAP signaling pathway is an evolutionarily conserved kinase cascade, and the YAP/TAZ downstream transcription activator plays an important role in organ size, tissue regeneration, and tumor suppression by controlling the proliferation, differentiation and apoptosis of cells [19]. Multiple studies have demonstrated the prominent role of YAP/TAZ in the CNS, including in neural development and neural diseases [37, 38]. YAP interacts with TEA domain transcription factor 1 (TEAD1), which results in an increased expression of cyclin D1 and the proliferation of neural stem cells [39]. The complex of phosphorylated YAP and $\beta$-catenin leads to inhibition of neural stem cells differentiation [40-42]. Our previous studies have expounded the important role and functionary mechanisms of the Wnt/ $\beta$-catenin signaling pathway in ischemic stroke [43], which implies that the Hippo/YAP signaling pathway plays a complex role in ischemic stroke.

YAP has also been reported to negatively regulate inflammatory signaling and astrocyte activation in brain injury; the BMP2/Neogenin/RhoA/YAP/Smad1 signaling pathway has been reported to regulate the 
differentiation of cortical astrocytes [44-47]. One study on Huntingtin's disease showed that neural death was partially caused by the loss of YAP/TEAD-dependent transcriptional function [48]. These results suggest that YAP or the Hippo/YAP signaling pathway may be involved in the occurrence and development of CNS diseases.

In recent years, research has indicated that the Hippo/YAP signaling pathway plays a role in stroke. One study reported that TEADs, the major transcriptional co-factor of YAP, mediated vascular smooth muscle cell proliferation and neointima formation by activating the SLC1A5-glutamine uptake axis, which could represent a promising curative strategy for vascular occlusive disease and ischemic stroke [49].

Mammalian Ste20-like kinase1 (MST1) is an important upstream factor that activates YAP and functions as the key kinase in Hippo/YAP signaling [50]. MST1 precipitates microglial activation and activates NF$\mathrm{KB}$, thus playing a crucial role in the pathological process of acute cerebral ischemic injury by controlling both neuronal cell death and microglial activation [51]. Furthermore, in hemorrhagic stroke, MST1 alleviates both early brain injury and secondary brain injury by reducing brain edema, blood-brain barrier (BBB) damage, and neuroinflammation [52, 53]. These studies indicate that Hippo/YAP is a promising therapeutic target for the treatment of cerebral stroke injury and perhaps also other neurological disorders. However, the role and mechanisms of action of the Hippo/YAP signaling pathway in cerebral disease and other CNS disorders are unclear, and further research is required.

IGF-1 is involved in many physiological, anabolic and metabolic processes and functions as a major homeostatic regulator in growth, development, life-span control and ageing in mammals. IGF-1 activates the phosphorylation of the insulin receptor substrate molecules, the PI3K/AKT signaling pathway, and the mitogen activated protein kinase (MAPK) signaling cascade, to control multiple cellular factors, including the mechanistic target of rapamycin (mTOR) activity and FoxO translocation [54].

Previous work has shown that IGF-1 is involved in the occurrence of multiple cancers through promoting cell growth and proliferation. While research has explored the possibility of targeting IGF-1 to prevent cancer progression, clinical trials have not been successful $[55,56]$. However, in hematological neoplasms, arsenite-inducible RNA-associated protein-like (AIRAPL) exerts anti-neoplastic functions by regulating IGF-1 expression [57]. Thus, IGF-1 may be a complex therapeutic target for the treatment of neoplastic disease $[58,59]$.

IGF-1 is a naturally occurring neurotrophic factor in the CNS that is essential for brain development and plasticity [60]. Circulating IGF-1 readily crosses the BBB into the cerebrospinal fluid and brain parenchyma via a saturable transport system [61]. Local paracrine production is thought to be the major source of IGF1 within the brain [62]. IGF-1 binds to its receptor IGF1R and activates MAPK and the PI3K/AKT signaling pathway to contribute to the control of neuronal excitability, nerve cell metabolism and cell survival in the CNS [63-65].

In an Alzheimer mouse model, IGF-1 protects against ABO-induced neuronal oxidative stress and loss of dendritic spines through inhibiting the binding of $A B O$ s to neurons [66], which suggests that IGF- 1 helps to prevent neuronal damage and memory loss [67]. IGF-1 also regulates the PI3K/AKT signaling pathway 
to decrease the phosphorylation of amyloid precursor protein (APP), which is a key stage in promoting amyloid plaque formation in Alzheimer's disease [68]. We can thus speculate that IGF-1 is involved in the pathophysiological process of many CNS diseases and may serve as a promising therapeutic target.

Recent studies have shown that circulating IGF-1 levels can predict cardiovascular events and ischemic stroke risk $[69,70]$. Higher IGF-1 levels have been associated with early carotid artery atherosclerosis [71]. Circulating IGF-1 levels are associated with a lower risk of incident ischemic stroke among adults, which is indicative of the involvement of IGF-1 in the pathogenesis of ischemic stroke [70]. Higher serum IGF-1 levels just after ischemic stroke onset has been associated with better neurological recovery and functional outcome [72], which suggests that endogenous IGF-1 levels also impact the evolution of cerebral infarction. While these studies present evidence of the involvement of IGF-1 in ischemic stroke, the precise mechanism of IGF-1 in ischemic stroke remains an important question.

The PI3K/AKT signaling pathway regulates YAP/TAZ expression and YAP in turn integrates PI3K/AKT cascade with mechanical and polarity cues, which has been found to result in tissue growth control in Drosophila [20]. In addition, PI3K is activated by IGF-1 [73]. Our previous study suggested that the Hippo/YAP signaling pathway mitigated brain damage by protecting the BBB in cerebral I/R injury [74]. Therefore, in the present study, we explored whether IGF-1 activates the Hippo/YAP signaling pathway to exert its neuroprotective effects following ischemic stroke, and whether these effects were mediated by the PI3K/AKT signaling pathway. As we hypothesized, IGF-1 activated the PI3K/AKT signaling pathway, leading to up-regulation of YAP/TAZ followed by neurological protection.

Our study has limitations. Previous studies showed that the levels of IGF-binding proteins may affect the actions of IGF-1 in ischemic stroke [75]. We did not measure biologically active IGF-binding proteins. The effect of IGF-1 in brain is highly correlated with the ratio of IGF-1 to IGF-binding proteins, and therefore, measuring IGF-1 alone may lead to an underestimation of the true relationships between IGF-1 and ischemic stroke. Further research is needed to illustrate the precise effects of IGF-1 in ischemic stroke, as well as its correlation with the Hippo/YAP signaling pathway.

\section{Conclusion}

In conclusion, our study indicates that IGF-1 activates the Hippo/YAP signaling pathway via regulation of the PI3K/p-AKT signaling pathway, which results in increased cell viability and decreased neural apoptosis in vitro, and decreased neurological deficits, neural death and apoptosis, and cerebral infarct volume in vivo. Additionally, we found evidence of obvious reactive proliferation of astrocytes and microglia in the rat ischemic brain. IGF-1 was expressed in astrocytes and microglia and its expression level increased alongside the proliferation of astrocytes and microglia. Furthermore, MAP2 + cells or neurons were decreased in the rat model of ischemic stroke and were up-regulated by IGF-1, which indicates that neuronal damage can be alleviated by IGF-1.

\section{Abbreviations}


IGF-1, Insulin-like Growth Factor 1; I/R, Ischemia-Reperfusion; DMEM, Dulbecco's minimal Eagle medium; FBS, Fetal Bovine Serum; OGD, Oxygen and Glucose Deprivation; DMSO, Dimethyl Sulfoxide; CCK-8, Cell Counting Kit-8; MCAO, Middle Cerebral Artery Occlusion; TTC, 2, 3, 5-triphenyltetrazoliumchloride; TUNEL, TdT-mediated dUTP Nick-End Labeling; CNS, Central Nervous System; MST1, Mammalian Ste20-like Kinase1; BBB, Blood-Brain Barrier; Mitogen Activated Protein Kinase, MAPK

\section{Declarations}

\section{Funding}

This study is supported by grants from National Natural Science Foundation of China (81171112, 81371272 , and 81971870 to M.C.L.).

\section{Competing interests}

The authors have no competing interests to declare.

\section{Ethics approval}

The protocols used were approved by the Institutional Animal Care and Use Committee of Wuhan University. All procedures adhered to the regulations specified by the National Institutes of Health Guide for the Care and Use of Laboratory Animals.

\section{Consent for publication}

Not applicable.

\section{Availability of data and materials}

They are available from the corresponding author on reasonable request during the current study.

\section{Author contributions}

G-P and Z-YC contributed to the study design, performed the experiments, and wrote the manuscript. G-P, Z-YC, Z-W, H-SM and T-Q contributed to the research data, analyzed the data and the discussion. X-Z and $\mathrm{C}-\mathrm{QX}$ contributed to reviewing and editing the manuscript. L-MC contributed to the study design and discussion and reviewed and edited the manuscript. All authors read and approved the final manuscript.

\section{References}

1. Arroba Al, Campos-Caro A, Aguilar-Diosdado M, Valverde AM (2018) IGF-1, Inflammation and Retinal Degeneration: A Close Network. Front Aging Neurosci 10:203. doi:10.3389/fnagi.2018.00203

2. Di Bona D, Accardi G, Virruso C, Candore G, Caruso C (2014) Association between genetic variations in the insulin/insulin-like growth factor (Igf-1) signaling pathway and longevity: a systematic review 
and meta-analysis. Curr Vasc Pharmacol 12:674-681. doi:10.2174/1570161111666131218152807

3. Costales J, Kolevzon A (2016) The therapeutic potential of insulin-like growth factor-1 in central nervous system disorders. Neurosci Biobehav Rev 63:207-222. doi:10.1016/j.neubiorev.2016.01.001

4. Bach MA, Shen-Orr Z, Lowe WL Jr, Roberts CT Jr, LeRoith D (1991) Insulin-like growth factor I mRNA levels are developmentally regulated in specific regions of the rat brain. Brain Res Mol Brain Res 10:43-48. doi:10.1016/0169-328x(91)90054-2

5. Almeida OP, Hankey GJ, Yeap BB, Chubb SAP, Gollege J, Flicker L (2018) Risk of prevalent and incident dementia associated with insulin-like growth factor and insulin-like growth factor-binding protein 3. Mol Psychiatry 23:1825-1829. doi:10.1038/mp.2017.152

6. Lu YJ, Sareddy GR, Wang J, Zhang QG, Tang FL, Pratap UP, Tekmal RR, Vadlamudi RK, Brann DW (2020) Neuron-Derived Estrogen Is Critical for Astrocyte Activation and Neuroprotection of the Ischemic Brain. J Neurosci 40:7355-7374. doi:10.1523/Jneurosci.0115-20.2020

7. Zhang JY, Liu MQ, Huang MH, Chen MF, Zhang D, Luo LP, Ye GN, Deng LJ, Peng YH, Wu X, Liu GP, Ye WC, Zhang DM (2019) Ginsenoside F1 promotes angiogenesis by activating the IGF-1/IGF1R pathway. Pharmacol Res 144:292-305. doi:10.1016/j.phrs.2019.04.021

8. Andrabi SS, Parvez S, Tabassum H (2020) Ischemic stroke and mitochondria: mechanisms and targets. Protoplasma 257:335-343. doi:10.1007/s00709-019-01439-2

9. Chesik D, De Keyser J, Wilczak N (2008) Insulin-like growth factor system regulates oligodendroglial cell behavior: therapeutic potential in CNS. J Mol Neurosci 35:81-90. doi:10.1007/s12031-008-90412

10. Torres-Aleman I (1999) Insulin-like growth factors as mediators of functional plasticity in the adult brain. Horm Metab Res 31:114-119. doi:10.1055/s-2007-978707

11. Torres Aleman I (2005) Role of insulin-like growth factors in neuronal plasticity and neuroprotection. Adv Exp Med Biol 567:243-258. doi:10.1007/0-387-26274-1_10

12. Lioutas VA, Alfaro-Martinez F, Bedoya F, Chung CC, Pimentel DA, Novak V (2015) Intranasal Insulin and Insulin-Like Growth Factor 1 as Neuroprotectants in Acute Ischemic Stroke. Transl Stroke Res 6:264-275. doi:10.1007/s12975-015-0409-7

13. Schwab S, Spranger M, Krempien S, Hacke W, Bettendorf M (1997) Plasma insulin-like growth factor I and IGF binding protein 3 levels in patients with acute cerebral ischemic injury. Stroke 28:17441748. doi:10.1161/01.str.28.9.1744

14. Denti L, Scoditti U, Tonelli C, Saccavini M, Caminiti C, Valcavi R, Benatti M, Ceda GP (2010) The poor outcome of ischemic stroke in very old people: a cohort study of its determinants. J Am Geriatr Soc 58:12-17. doi:10.1111/j.1532-5415.2009.02616.x

15. Sohrabji F (2015) Estrogen-IGF-1 interactions in neuroprotection: ischemic stroke as a case study. Front Neuroendocrinol 36:1-14. doi:10.1016/j.yfrne.2014.05.003

16. Rizk NN, Myatt-Jones J, Rafols J, Dunbar JC (2007) Insulin like growth factor-1 (IGF-1) decreases ischemia-reperfusion induced apoptosis and necrosis in diabetic rats. Endocrine 31:66-71. doi:10.1007/s12020-007-0012-0 
17. Vincent AM, Mobley BC, Hiller A, Feldman EL (2004) IGF-I prevents glutamate-induced motor neuron programmed cell death. Neurobiol Dis 16:407-416. doi:10.1016/j.nbd.2004.03.001

18. Fernandez AM, Torres-Aleman I (2012) The many faces of insulin-like peptide signalling in the brain. Nat Rev Neurosci 13:225-239. doi:10.1038/nrn3209

19. Gong P, Zhang Z, Zou CL, Tian Q, Chen XM, Hong M, Liu X, Chen QX, Xu Z, Li MC, Wang J (2019) Hippo/YAP signaling pathway mitigates blood-brain barrier disruption after cerebral ischemia/reperfusion injury. Behavioural Brain Research, pp. 8-17

20. Borreguero-Munoz N, Fletcher GC, Aguilar-Aragon M, Elbediwy A, Vincent-Mistiaen ZI, Thompson BJ (2019) The Hippo pathway integrates PI3K-Akt signals with mechanical and polarity cues to control tissue growth. PLoS Biol 17:e3000509. doi:10.1371/journal.pbio.3000509

21. Jiang W, Zhang S, Fu F, Zhu H, Hou J (2010) Inhibition of nuclear factor-kappaB by 6-O-acetyl shanzhiside methyl ester protects brain against injury in a rat model of ischemia and reperfusion. $J$ Neuroinflammation 7:55. doi:10.1186/1742-2094-7-55

22. McCune CD, Chan SJ, Beio ML, Shen W, Chung WJ, Szczesniak LM, Chai C, Koh SQ, Wong PT, Berkowitz DB (2016) "Zipped Synthesis" by Cross-Metathesis Provides a Cystathionine betaSynthase Inhibitor that Attenuates Cellular H2S Levels and Reduces Neuronal Infarction in a Rat Ischemic Stroke Model. ACS Cent Sci 2:242-252. doi:10.1021/acscentsci.6b00019

23. Li M, Feng B, Wang L, Guo S, Zhang P, Gong J, Zhang Y, Zheng A, Li H (2015) Tollip is a critical mediator of cerebral ischaemia-reperfusion injury. J Pathol 237:249-262. doi:10.1002/path.4565

24. Carter AN, Downest CP (1995) Molecular mechanisms of regulation of phosphoinositide 3-kinase by insulin, insulin-like growth factor I and nerve growth factor in PC12 cells. Biochem Soc Trans 23:148-152. doi:10.1042/bst0230148

25. Jones DM, Tucker BA, Rahimtula M, Mearow KM (2003) The synergistic effects of NGF and IGF-1 on neurite growth in adult sensory neurons: convergence on the PI 3-kinase signaling pathway. J Neurochem 86:1116-1128. doi:10.1046/j.1471-4159.2003.01925.x

26. Leloup C, Michaelson DM, Fisher A, Hartmann T, Beyreuther K, Stein R (2000) M1 muscarinic receptors block caspase activation by phosphoinositide 3-kinase- and MAPK/ERK-independent pathways. Cell Death Differ 7:825-833. DOI 10.1038/sj.cdd.4400713 doi

27. D'Mello SR, Borodezt K, Soltoff SP (1997) Insulin-like growth factor and potassium depolarization maintain neuronal survival by distinct pathways: Possible involvement of PI 3-kinase in IGF-1 signaling. J Neurosci 17:1548-1560

28. Li M, Zhang Z, Sun W, Koehler RC, Huang J (2011) 17beta-estradiol attenuates breakdown of bloodbrain barrier and hemorrhagic transformation induced by tissue plasminogen activator in cerebral ischemia. Neurobiol Dis 44:277-283. doi:10.1016/j.nbd.2011.07.004

29. Schabitz WR, Hoffmann TT, Heiland S, Kollmar R, Bardutzky J, Sommer C, Schwab S (2001) Delayed neuroprotective effect of insulin-like growth factor-I after experimental transient focal cerebral ischemia monitored with MRI. Stroke 32:1226-1233. Doi 10.1161/01.Str.32.5.1226 doi 
30. Zhu Q, Enkhjargal B, Huang L, Zhang T, Sun C, Xie Z, Wu P, Mo J, Tang J, Xie Z, Zhang JH (2018) Aggf1 attenuates neuroinflammation and BBB disruption via PI3K/Akt/NF-kappaB pathway after subarachnoid hemorrhage in rats. J Neuroinflammation 15:178. doi:10.1186/s12974-018-1211-8

31. Gong P, Zhang Z, Zou Y, Tian Q, Han S, Xu Z, Liao J, Gao L, Chen Q, Li M (2019) Tetramethylpyrazine attenuates blood-brain barrier disruption in ischemia/reperfusion injury through the JAK/STAT signaling pathway. Eur J Pharmacol 854:289-297. doi:10.1016/j.ejphar.2019.04.028

32. Wang J, Yu L, Jiang C, Chen M, Ou C, Wang J (2013) Bone marrow mononuclear cells exert long-term neuroprotection in a rat model of ischemic stroke by promoting arteriogenesis and angiogenesis. Brain Behav Immun 34:56-66. doi:10.1016/j.bbi.2013.07.010

33. Jiang C, Wang J, Yu L, Ou C, Liu X, Zhao X, Wang J (2013) Comparison of the therapeutic effects of bone marrow mononuclear cells and microglia for permanent cerebral ischemia. Behav Brain Res 250:222-229. doi:10.1016/j.bbr.2013.05.011

34. Zou Y, Gong P, Zhao W, Zhang J, Wu X, Xin C, Xiong Z, Li Z, Wu X, Wan Q, Li X, Chen J (2019) Quantitative iTRAQ-based proteomic analysis of piperine protected cerebral ischemia/reperfusion injury in rat brain. Neurochem Int 124:51-61. doi:10.1016/j.neuint.2018.12.010

35. Gong P, Li M, Zou C, Tian Q, Xu Z (2018) Tissue Plasminogen Activator Causes Brain Microvascular Endothelial Cell Injury After Oxygen Glucose Deprivation by Inhibiting Sonic Hedgehog Signaling. Neurochem Res doi. 10.1007/s11064-018-2697-2

36. Gong P, Li M, Zou C, Tian Q, Xu Z (2019) Tissue Plasminogen Activator Causes Brain Microvascular Endothelial Cell Injury After Oxygen Glucose Deprivation by Inhibiting Sonic Hedgehog Signaling. Neurochem Res 44:441-449. doi:10.1007/s11064-018-2697-2

37. Kostic M, Paridaen JTML, Long KR, Kalebic N, Langen B, Grubling N, Wimberger P, Kawasaki H, Namba T, Huttner WB (2019) YAP Activity Is Necessary and Sufficient for Basal Progenitor Abundance and Proliferation in the Developing Neocortex. Cell Reports 27:1103-1103+. doi:10.1016/j.celrep.2019.03.091

38. Wang XH, Valls AF, Schermann G, Shen Y, Moya IM, Castro L, Urban S, Solecki GM, Winkler F, Riedemann L, Jain RK, Mazzone M, Schmidt T, Fischer T, Halder G, de Almodovar CR (2017) YAP/TAZ Orchestrate VEGF Signaling during Developmental Angiogenesis. Dev Cell 42:462-462+. doi:10.1016/j.devcel.2017.08.002

39. Yao M, Wang Y, Zhang P, Chen H, Xu Z, Jiao J, Yuan Z (2014) BMP2-SMAD signaling represses the proliferation of embryonic neural stem cells through YAP. J Neurosci 34:12039-12048. doi:10.1523/JNEUROSCI.0486-14.2014

40. Musah S, Wrighton PJ, Zaltsman Y, Zhong X, Zorn S, Parlato MB, Hsiao C, Palecek SP, Chang Q, Murphy WL, Kiessling LL (2014) Substratum-induced differentiation of human pluripotent stem cells reveals the coactivator YAP is a potent regulator of neuronal specification. Proc Natl Acad Sci U S A 111:13805-13810. doi:10.1073/pnas.1415330111

41. Rammensee S, Kang MS, Georgiou K, Kumar S, Schaffer DV (2017) Dynamics of Mechanosensitive Neural Stem Cell Differentiation. Stem Cells 35:497-506. doi:10.1002/stem.2489 
42. Sun Y, Yong KM, Villa-Diaz LG, Zhang X, Chen W, Philson R, Weng S, Xu H, Krebsbach PH, Fu J (2014) Hippo/YAP-mediated rigidity-dependent motor neuron differentiation of human pluripotent stem cells. Nat Mater 13:599-604. doi:10.1038/nmat3945

43. Wang W, Li M, Wang Y, Li Q, Deng G, Wan J, Yang Q, Chen Q, Wang J (2016) GSK-3beta inhibitor TWS119 attenuates rtPA-induced hemorrhagic transformation and activates the Wnt/beta-catenin signaling pathway after acute ischemic stroke in rats. Mol Neurobiol 53:7028-7036. doi:10.1007/s12035-015-9607-2

44. Huang Z, Sun D, Hu JX, Tang FL, Lee DH, Wang Y, Hu G, Zhu XJ, Zhou J, Mei L, Xiong WC (2016) Neogenin Promotes BMP2 Activation of YAP and Smad1 and Enhances Astrocytic Differentiation in Developing Mouse Neocortex. J Neurosci 36:5833-5849. doi:10.1523/JNEUROSCI.4487-15.2016

45. Lopez-Anido C, Poitelon Y, Gopinath C, Moran JJ, Ma KH, Law WD, Antonellis A, Feltri ML, Svaren J (2016) Tead1 regulates the expression of Peripheral Myelin Protein 22 during Schwann cell development. Hum Mol Genet 25:3055-3069. doi:10.1093/hmg/ddw158

46. Huang Z, Xiong WC (2016) Neogenin-YAP signaling in neocortical astrocytic differentiation. Neurogenesis (Austin) 3:e1248735. doi:10.1080/23262133.2016.1248735

47. Shimizu T, Osanai Y, Tanaka KF, Abe M, Natsume R, Sakimura K, Ikenaka K (2017) YAP functions as a mechanotransducer in oligodendrocyte morphogenesis and maturation. Glia 65:360-374. doi:10.1002/glia.23096

48. Mao Y, Chen X, Xu M, Fujita K, Motoki K, Sasabe T, Homma H, Murata M, Tagawa K, Tamura T, Kaye J, Finkbeiner S, Blandino G, Sudol M, Okazawa H (2016) Targeting TEAD/YAP-transcriptiondependent necrosis, TRIAD, ameliorates Huntington's disease pathology. Hum Mol Genet 25:47494770. doi:10.1093/hmg/ddw303

49. Osman I, He X, Liu J, Dong K, Wen T, Zhang F, Yu L, Hu G, Xin H, Zhang W, Zhou J (2019) TEAD1 (TEA Domain Transcription Factor 1) Promotes Smooth Muscle Cell Proliferation Through Upregulating SLC1A5 (Solute Carrier Family 1 Member 5)-Mediated Glutamine Uptake. Circ Res 124:1309-1322. doi:10.1161/CIRCRESAHA.118.314187

50. Lange AW, Sridharan A, Xu Y, Stripp BR, Perl AK, Whitsett JA (2015) Hippo/Yap signaling controls epithelial progenitor cell proliferation and differentiation in the embryonic and adult lung. $\mathrm{J}$ Mol Cell Biol 7:35-47. doi:10.1093/jmcb/mju046

51. Zhao S, Yin J, Zhou L, Yan F, He Q, Huang L, Peng S, Jia J, Cheng J, Chen H, Tao W, Ji X, Xu Y, Yuan Z (2016) Hippo/MST1 signaling mediates microglial activation following acute cerebral ischemiareperfusion injury. Brain Behav Immun 55:236-248. doi:10.1016/j.bbi.2015.12.016

52. Zhang P, Wang T, Zhang D, Zhang Z, Yuan S, Zhang J, Cao J, Li H, Li X, Shen H, Chen G (2019) Exploration of MST1-Mediated Secondary Brain Injury Induced by Intracerebral Hemorrhage in Rats via Hippo Signaling Pathway. Transl Stroke Res 10:729-743. doi:10.1007/s12975-019-00702-1

53. Qu J, Zhao H, Li Q, Pan P, Ma K, Liu X, Feng H, Chen Y (2018) MST1 Suppression Reduces Early Brain Injury by Inhibiting the NF-kappaB/MMP-9 Pathway after Subarachnoid Hemorrhage in Mice. Behav Neurol 2018:6470957. doi:10.1155/2018/6470957 
54. Milman S, Huffman DM, Barzilai N (2016) The Somatotropic Axis in Human Aging: Framework for the Current State of Knowledge and Future Research. Cell Metab 23:980-989. doi:10.1016/j.cmet.2016.05.014

55. Fuchs CS, Azevedo S, Okusaka T, Van Laethem JL, Lipton LR, Riess H, Szczylik C, Moore MJ, Peeters M, Bodoky G, Ikeda M, Melichar B, Nemecek R, Ohkawa S, Swieboda-Sadlej A, Tjulandin SA, Van Cutsem E, Loberg R, Haddad V, Gansert JL, Bach BA, Carrato A (2015) A phase 3 randomized, doubleblind, placebo-controlled trial of ganitumab or placebo in combination with gemcitabine as first-line therapy for metastatic adenocarcinoma of the pancreas: the GAMMA trial. Ann Oncol 26:921-927. doi:10.1093/annonc/mdv027

56. Robertson JF, Ferrero JM, Bourgeois H, Kennecke H, de Boer RH, Jacot W, McGreivy J, Suzuki S, Zhu M, McCaffery I, Loh E, Gansert JL, Kaufman PA (2013) Ganitumab with either exemestane or fulvestrant for postmenopausal women with advanced, hormone-receptor-positive breast cancer: a randomised, controlled, double-blind, phase 2 trial. Lancet Oncol 14:228-235. doi:10.1016/S14702045(13)70026-3

57. Osorio FG, Soria-Valles C, Santiago-Fernandez O, Bernal T, Mittelbrunn M, Colado E, Rodriguez F, Bonzon-Kulichenko E, Vazquez J, Porta-de-la-Riva M, Ceron J, Fueyo A, Li J, Green AR, Freije JM, Lopez-Otin C (2016) Loss of the proteostasis factor AIRAPL causes myeloid transformation by deregulating IGF-1 signaling. Nat Med 22:91-96. doi:10.1038/nm.4013

58. Moellendorf S, Kessels C, Peiseler L, Raupach A, Jacoby C, Vogt N, Lindecke A, Koch L, Bruning J, Heger J, Kohrer K, Godecke A (2012) IGF-IR signaling attenuates the age-related decline of diastolic cardiac function. Am J Physiol Endocrinol Metab 303:E213-E222. doi:10.1152/ajpendo.00538.2011

59. Levine ME, Suarez JA, Brandhorst S, Balasubramanian P, Cheng CW, Madia F, Fontana L, Mirisola MG, Guevara-Aguirre J, Wan J, Passarino G, Kennedy BK, Wei M, Cohen P, Crimmins EM, Longo VD (2014) Low protein intake is associated with a major reduction in IGF-1, cancer, and overall mortality in the 65 and younger but not older population. Cell Metab 19:407-417.

doi:10.1016/j.cmet.2014.02.006

60. Cheng CM, Reinhardt RR, Lee WH, Joncas G, Patel SC, Bondy CA (2000) Insulin-like growth factor 1 regulates developing brain glucose metabolism. Proc Natl Acad Sci U S A 97:10236-10241. doi:10.1073/pnas.170008497

61. Muller AP, Fernandez AM, Haas C, Zimmer E, Portela LV, Torres-Aleman I (2012) Reduced brain insulin-like growth factor I function during aging. Mol Cell Neurosci 49:9-12. doi:10.1016/j.mcn.2011.07.008

62. Torres-Aleman I (2010) Toward a comprehensive neurobiology of IGF-I. Dev Neurobiol 70:384-396. doi:10.1002/dneu.20778

63. Bassil F, Fernagut PO, Bezard E, Meissner WG (2014) Insulin, IGF-1 and GLP-1 signaling in neurodegenerative disorders: targets for disease modification? Prog Neurobiol 118:1-18. doi:10.1016/j.pneurobio.2014.02.005 
64. Yoshii A, Constantine-Paton M (2007) BDNF induces transport of PSD-95 to dendrites through PI3KAKT signaling after NMDA receptor activation. Nat Neurosci 10:702-711. doi:10.1038/nn1903

65. Sweatt JD (2001) The neuronal MAP kinase cascade: a biochemical signal integration system subserving synaptic plasticity and memory. J Neurochem 76:1-10. doi:10.1046/j.14714159.2001.00054.x

66. Selles MC, Fortuna JTS, Zappa-Villar MF, de Faria YPR, Souza AS, Suemoto CK, Leite REP, Rodriguez RD, Grinberg LT, Reggiani PC, Ferreira ST (2020) Adenovirus-Mediated Transduction of Insulin-Like Growth Factor 1 Protects Hippocampal Neurons from the Toxicity of Abeta Oligomers and Prevents Memory Loss in an Alzheimer Mouse Model. Mol Neurobiol 57:1473-1483. doi:10.1007/s12035019-01827-y

67. George C, Gontier G, Lacube P, Francois JC, Holzenberger M, Aid S (2017) The Alzheimer's disease transcriptome mimics the neuroprotective signature of IGF-1 receptor-deficient neurons. Brain 140:2012-2027. doi:10.1093/brain/awx132

68. Kim B, Elzinga SE, Henn RE, McGinley LM, Feldman EL (2019) The effects of insulin and insulin-like growth factor I on amyloid precursor protein phosphorylation in in vitro and in vivo models of Alzheimer's disease. Neurobiol Dis 132:104541. doi:10.1016/j.nbd.2019.104541

69. Erlandsson MC, Lyngfelt L, Aberg ND, Wasen C, Espino RA, Silfversward ST, Nadali M, Jood K, Andersson KME, Pullerits R, Bokarewa MI (2019) Low serum IGF1 is associated with hypertension and predicts early cardiovascular events in women with rheumatoid arthritis. BMC Med 17:141. doi:10.1186/s12916-019-1374-x

70. Saber H, Himali JJ, Beiser AS, Shoamanesh A, Pikula A, Roubenoff R, Romero JR, Kase CS, Vasan RS, Seshadri S (2017) Serum Insulin-Like Growth Factor 1 and the Risk of Ischemic Stroke: The Framingham Study. Stroke 48:1760-1765. doi:10.1161/STROKEAHA.116.016563

71. Kawachi S, Takeda N, Sasaki A, Kokubo Y, Takami K, Sarui H, Hayashi M, Yamakita N, Yasuda K (2005) Circulating insulin-like growth factor- 1 and insulin-like growth factor binding protein-3 are associated with early carotid atherosclerosis. Arterioscler Thromb Vasc Biol 25:617-621. doi:10.1161/01.ATV.0000154486.03017.35

72. De Smedt A, Brouns R, Uyttenboogaart M, De Raedt S, Moens M, Wilczak N, Luijckx GJ, De Keyser J (2011) Insulin-like growth factor I serum levels influence ischemic stroke outcome. Stroke 42:21802185. doi:10.1161/STROKEAHA. 110.600783

73. Wang M, Liang X, Cheng M, Yang L, Liu H, Wang X, Sai N, Zhang X (2019) Homocysteine enhances neural stem cell autophagy in in vivo and in vitro model of ischemic stroke. Cell Death Dis 10:561. doi:10.1038/s41419-019-1798-4

74. Gong P, Zhang Z, Zou C, Tian Q, Chen X, Hong M, Liu X, Chen Q, Xu Z, Li M, Wang J (2019) Hippo/YAP signaling pathway mitigates blood-brain barrier disruption after cerebral ischemia/reperfusion injury. Behav Brain Res 356:8-17. doi:10.1016/j.bbr.2018.08.003

75. Barton PJR, Felkin LE, Birks EJ, Cullen ME, Banner NR, Grindle S, Hall JL, Miller LW, Yacoub MH (2005) Myocardial insulin-like growth factor-I gene expression during recovery from heart failure after 


\section{Figures}

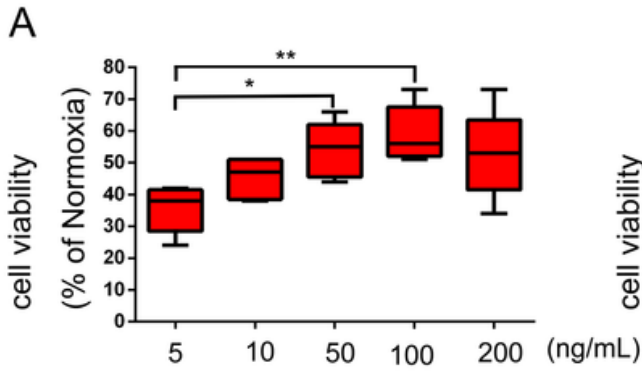

PC12 cells
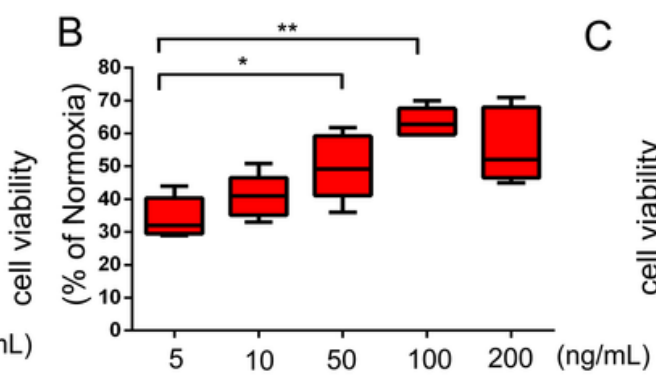

SH-SY5Y cells

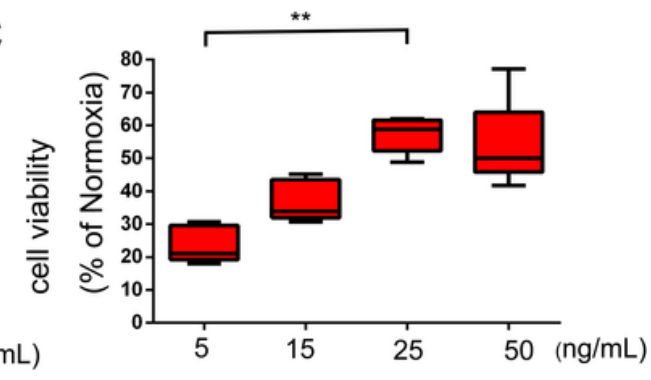

Primary neurons

\section{Figure 1}

Cell viability and apoptosis were measured in PC12 cells, SH-SY5Y cells and primary neurons that underwent OGD. (A) CCK-8 assay measured the cell viability of PC12 cells that underwent OGD and were treated with different concentrations of IGF-1 $(5 \mathrm{ng} / \mathrm{mL}, 10 \mathrm{ng} / \mathrm{mL}, 50 \mathrm{ng} / \mathrm{mL}, 100 \mathrm{ng} / \mathrm{mL}$ and 200 $\mathrm{ng} / \mathrm{mL}$ ). (B) CCK-8 assay measured the cell viability of SH-SY5Y cells that underwent OGD and were treated with different concentrations of IGF- $1(5 \mathrm{ng} / \mathrm{mL}, 10 \mathrm{ng} / \mathrm{mL}, 50 \mathrm{ng} / \mathrm{mL}, 100 \mathrm{ng} / \mathrm{mL}$ and 200 $\mathrm{ng} / \mathrm{mL}$ ). (C) CCK-8 assay measured the cell viability of primary neurons that underwent OGD and treated with different concentrations of IGF-1 ( $5 \mathrm{ng} / \mathrm{mL}, 15 \mathrm{ng} / \mathrm{mL}, 25 \mathrm{ng} / \mathrm{mL}$ and $50 \mathrm{ng} / \mathrm{mL})$. ${ }^{\star} \mathrm{P}<0.05$, $* \star \mathrm{P}<$ 0.01 . 


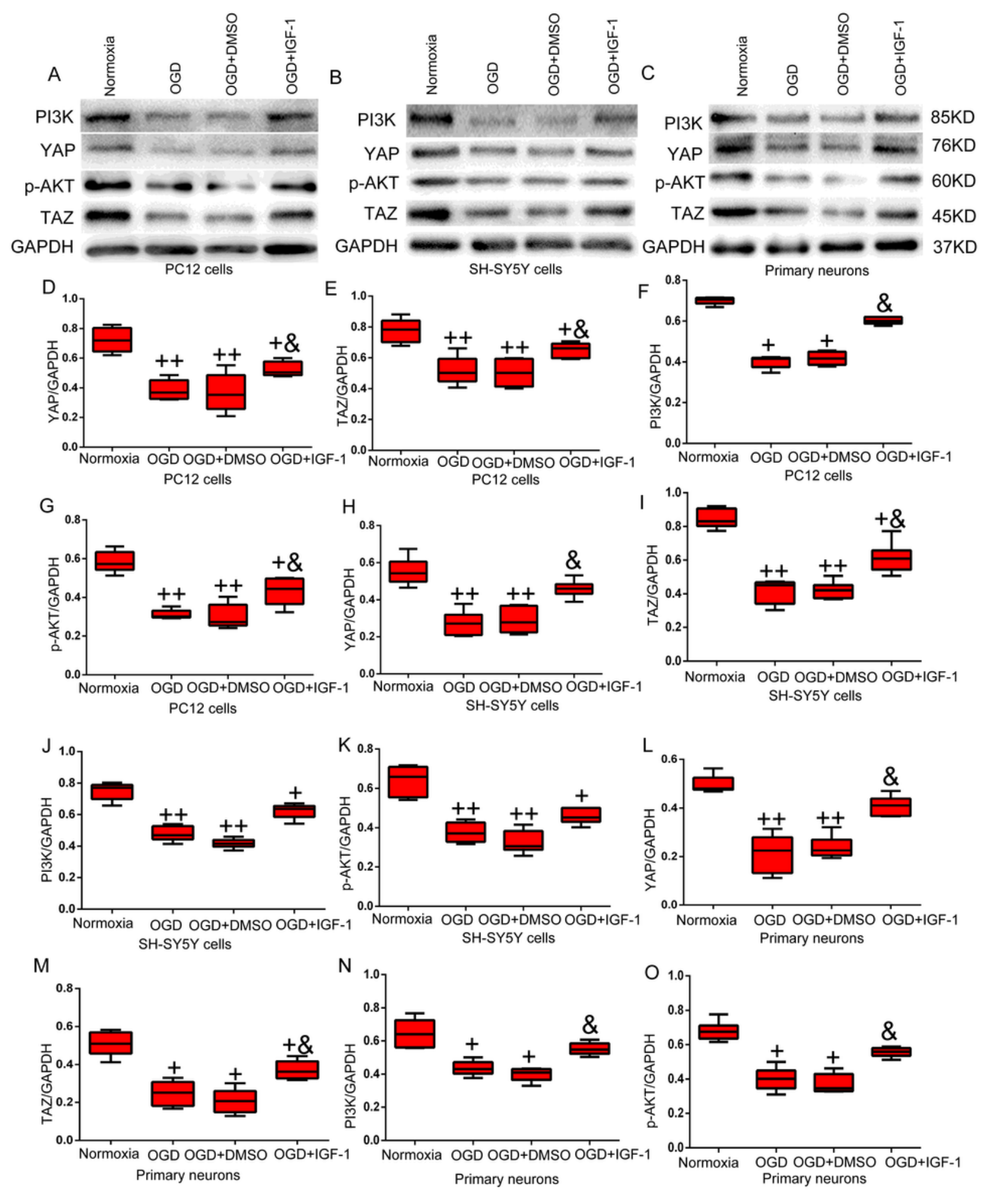

\section{Figure 2}

IGF-1 increased the expression of YAP/TAZ and activated the PI3K/AKT signaling pathway in different cells and groups. (A) Western blots showing the expressions of YAP/TAZ and PI3K/AKT in the different cells and groups. The levels of YAP/TAZ and PI3K/p-AKT decreased in the cells that underwent OGD. These decreases were reversed by IGF-1. GAPDH was used as loading control. (D-0) Quantified levels of 
YAP/TAZ and PI3K/p-AKT in the different cells and groups. $+\mathrm{P}<0.05,++\mathrm{P}<0.01$ vs. the Normoxia group; $\& \mathrm{P}<0.05$ vs. the OGD group.

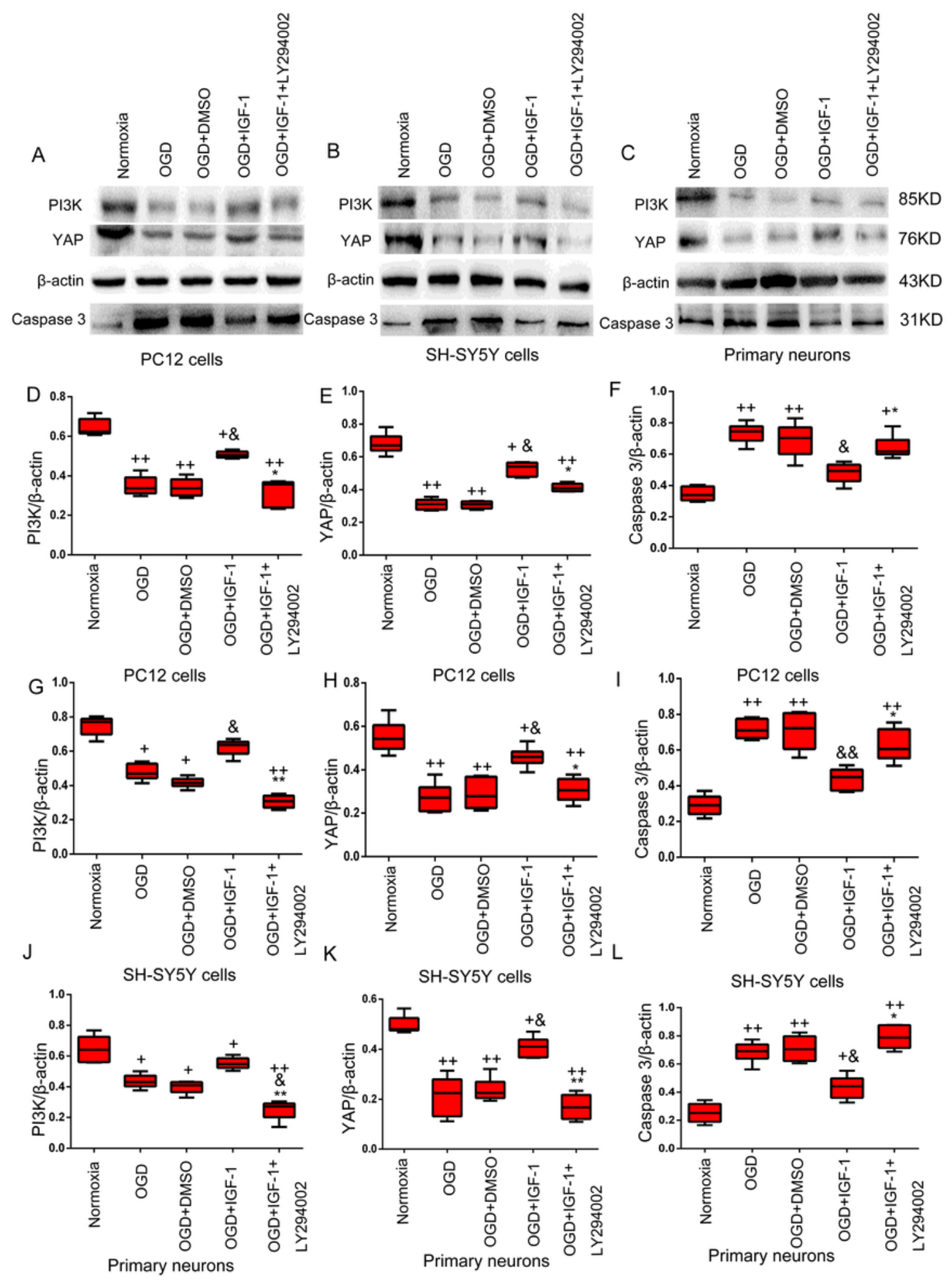

Figure 3

Expression levels of YAP, PI3K and Caspase 3 in the different cells and groups. (A-C) IGF-1 increased the expressions of YAP and PI3K, and decreased the expression of Caspase 3. Up-regulation of YAP and PI3K and down-regulation of Caspase 3 were reversed by LY294002 treatment. $\beta$-actin was used as loading 
control. (D-L) Quantified levels of YAP, PI3K and Caspase 3 in the different cells and groups. $+\mathrm{P}<0.05$, $++\mathrm{P}<0.01$ vs. the Normoxia group; \&P $<0.05$, \&\&P $<0.01$ vs. the OGD group; ${ }^{P}<0.05, * * P<0.01$ vs. the OGD+IGF-1 group.

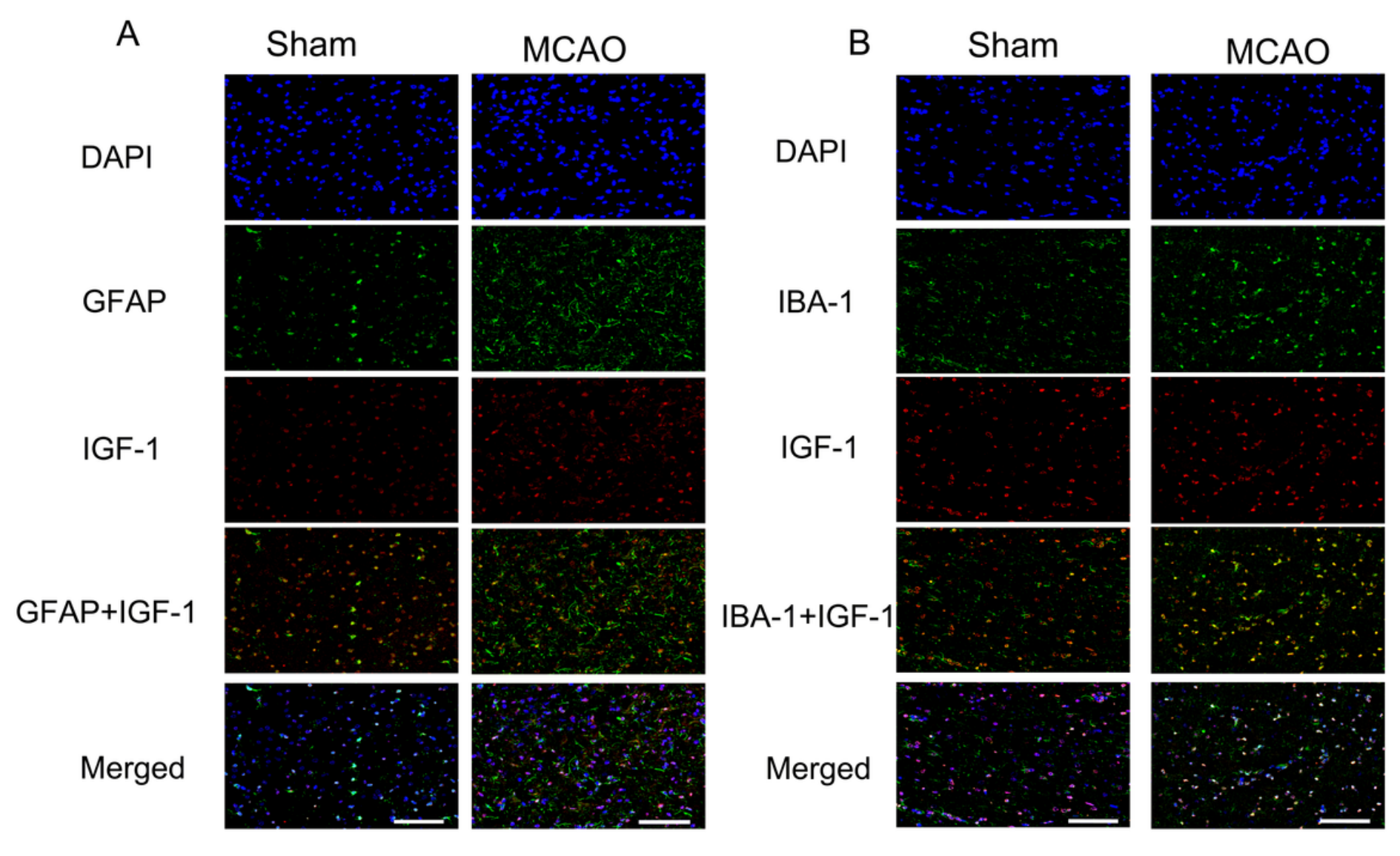

\section{Figure 4}

Immunofluorescence staining results of GFAP, IBA-1 and IGF-1 in brain tissue. (A) Double immunofluorescence staining of GFAP and IGF-1 showed that IGF-1 was expressed in astrocytes and that astrocyte count and IGF-1 expression level were elevated in the MCAO group ( $n=5$ rats per group, scale bar $=100 \mu \mathrm{m}, 200 x$ magnification). (B) Double immunofluorescence staining of IBA-1 and IGF-1 showed that IGF-1 was expressed in microglial cells and that the microglia count and IGF-1 expression level were elevated in the MCAO group ( $\mathrm{n}=5$ rats per group, scale bar $=100 \mu \mathrm{m}, 200 \mathrm{x}$ magnification). 

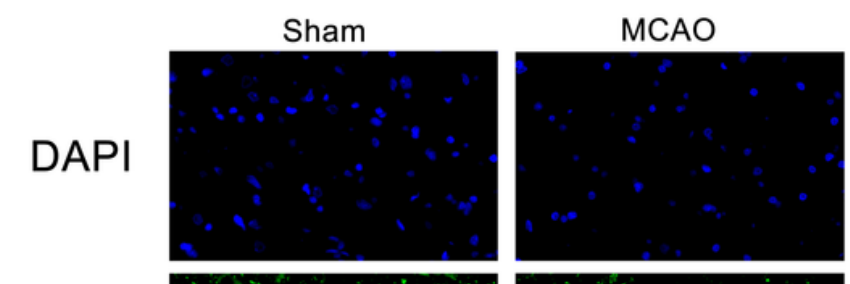

MCAO+DMSO
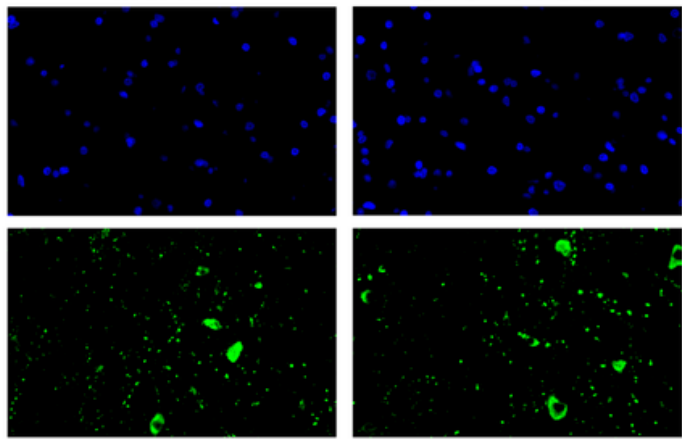

MAP2
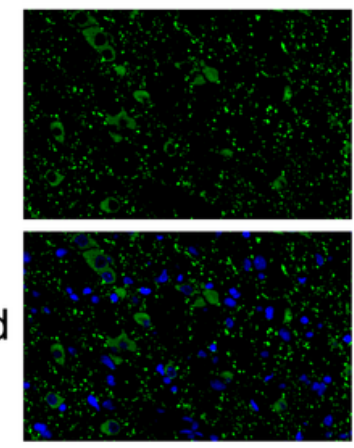
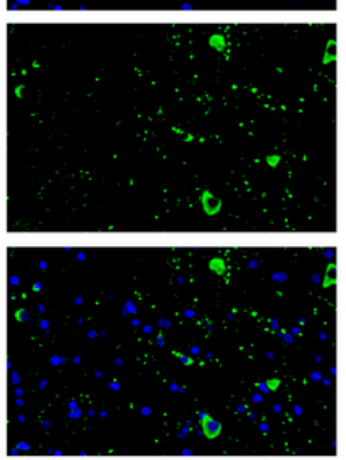

MCAO+IGF-1
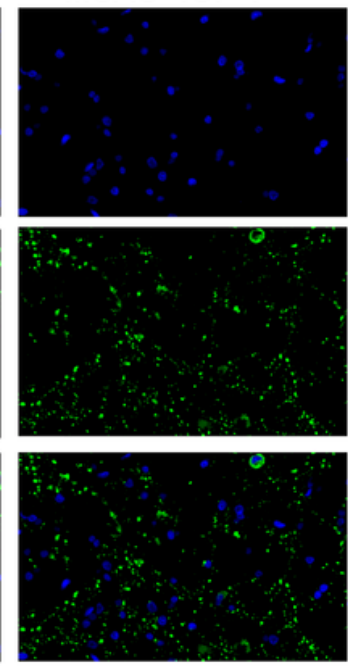

MCAO+IGF-1+LY294002
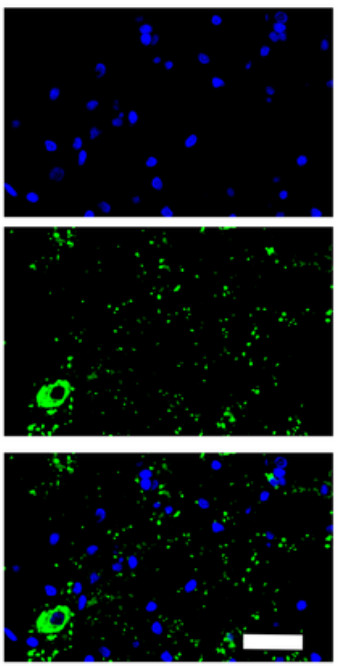

\section{Figure 5}

Expression of MAP2 in the different groups. MAP2 expression level was lower in the MCAO group and MCAO+DMSO group compared to the Sham group. IGF-1 increased the MAP2 expression and this effect of IGF-1 was reversed to some extent by LY294002 ( $n=5$ rats per group, scale bar $=50 \mu \mathrm{m}, 400 x$ magnification). 


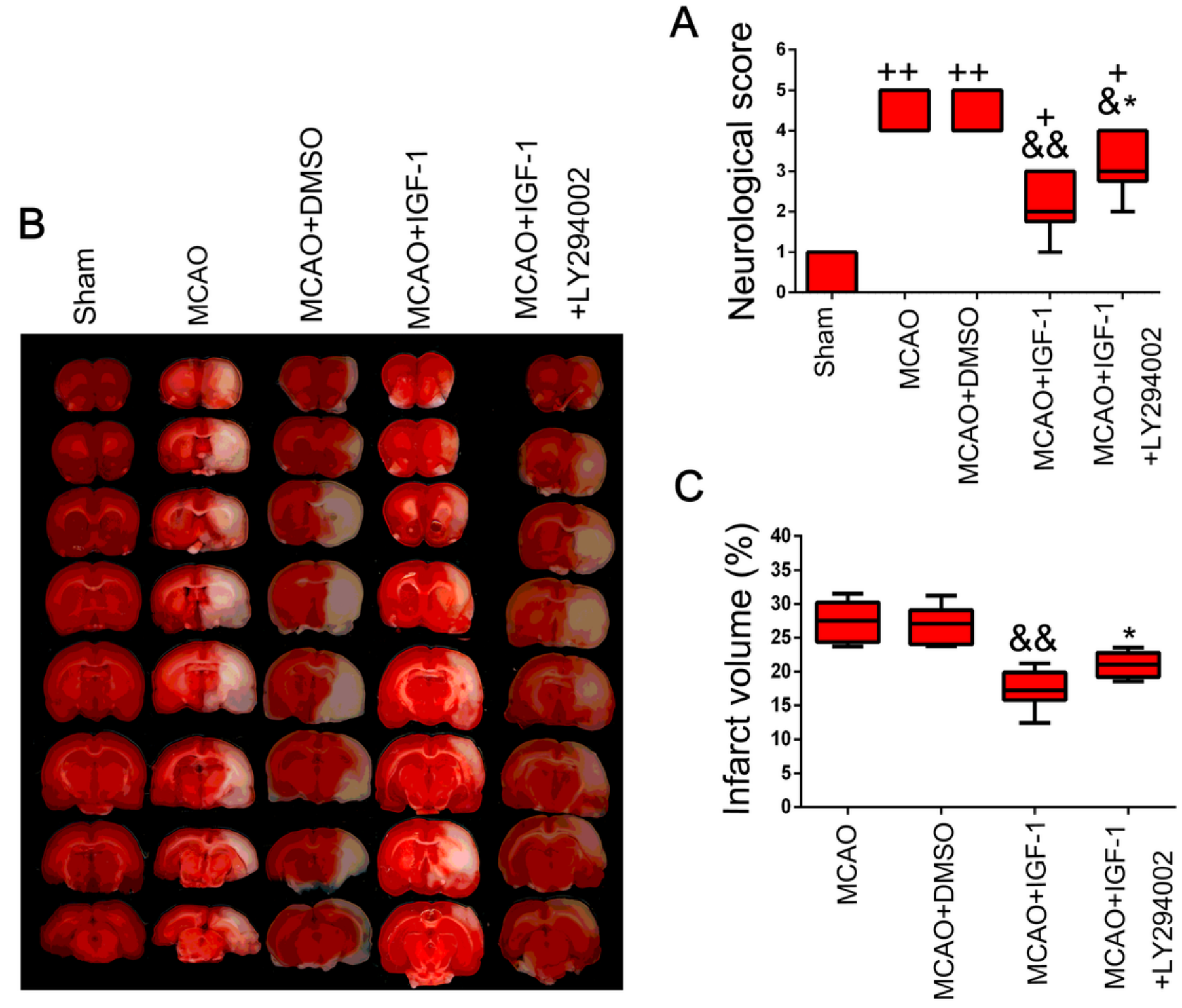

Figure 6

IGF-1 reduced neurological deficits and infarct volume. (A) Neurological deficit scores were lower in IGF1-treated rats than in untreated and vehicle-treated rats ( $n=15$ rats per group). (B) Representative images of TTC-stained brain slices from Sham-operated and MCAO-injured rats ( $\mathrm{n}=5$ rats per group). (C) Quantification of the infarct volume showed that IGF-1 reduced the infarct volume and that the protective effect of IGF-1 was reversed by LY294002. The percentage of infarct volume was $27.2 \%$ in the MCAO group, $25.1 \%$ in the MCAO+DMSO group, $15.6 \%$ in the MCAO+IGF-1 group, and $21.3 \%$ in the MCAO+IGF$1+$ LY294002 group. $+p<0.05,++p<0.01$ vs. the Sham group; \&p < 0.05, \&\&p<0.01 vs. the MCAO group; ${ }^{*} \mathrm{p}<0.05$ vs. the MCAO+IGF-1 group. 

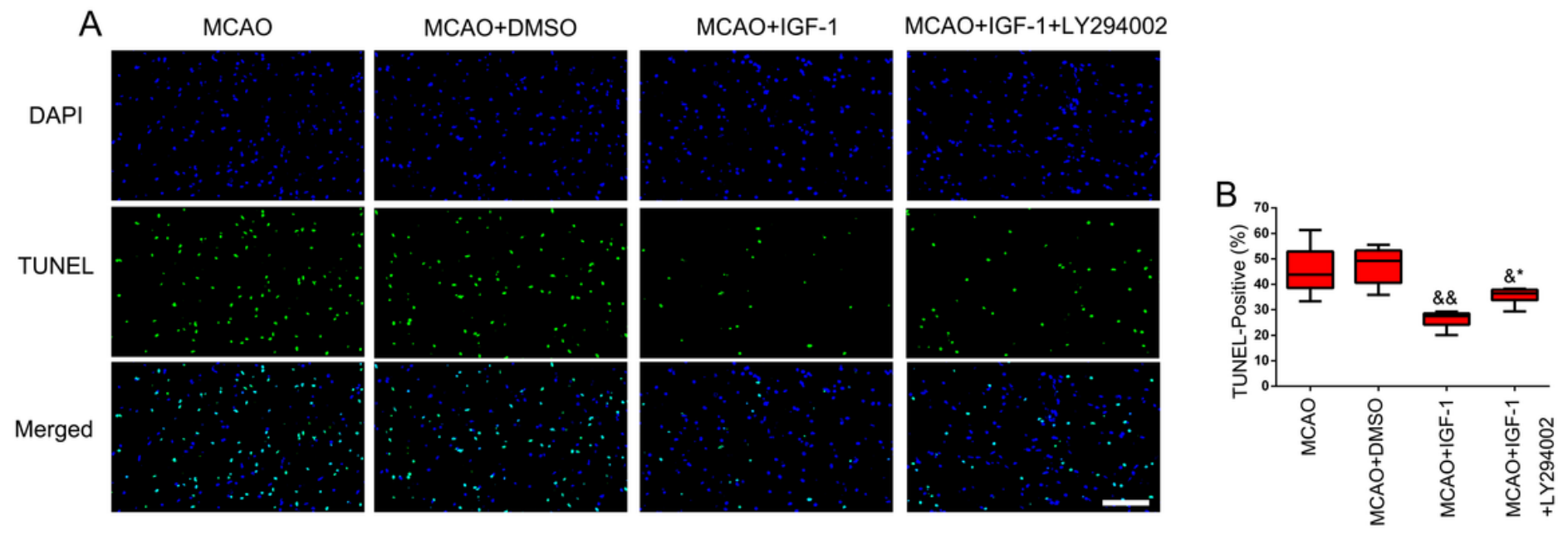

\section{Figure 7}

IGF-1 attenuated apoptosis induced by I/R injury. (A) TUNEL staining in the cortex of the different groups ( $n=5$ rats per group, scale bar $=100 \mu \mathrm{m}, 200 x$ magnification). (B) Quantitative analysis of apoptosis in the groups. The percentage of apoptotic cells was $45.1 \%$ in the MCAO group, $47.2 \%$ in the MCAO+DMSO group, $24.5 \%$ in the MCAO+IGF-1 group, and 34.5\% in the MCAO+IGF-1+LY294002 group. \&p < 0.05, \&\&p < 0.01 vs. the MCAO group; * $<0.05$ vs. the MCAO+IGF-1 group.

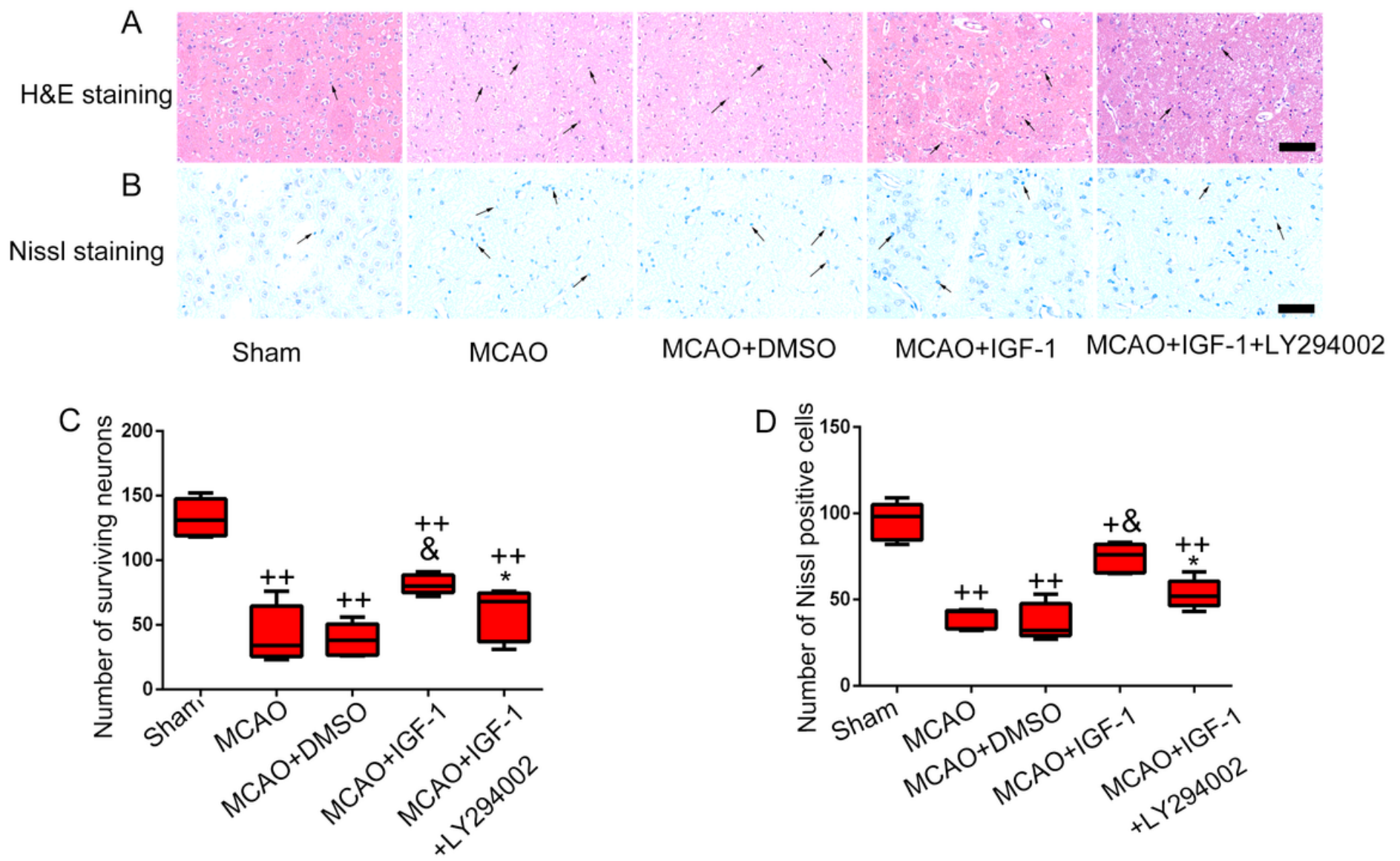

Figure 8 
IGF-1 protected neurons against I/R injury. Compared with the Sham group, the MCAO group and MCAO + DMSO group showed (A) apparent brain edema, abnormal neurons, and (B) irregularly arranged Nissl substance. The MCAO+IGF-1 group showed partial edema, more surviving neurons and increased visible Nissl substance ( $n=5$ rats per group). Arrows indicate necrotic nuclei. (C-D) Quantified levels of surviving neurons and Nissl-positive cells. $+p<0.05,++p<0.01$ vs. the Sham group; \&p $<0.05$ vs. the MCAO group; ${ }^{*} p<0.05$ vs. the MCAO+IGF-1 group.
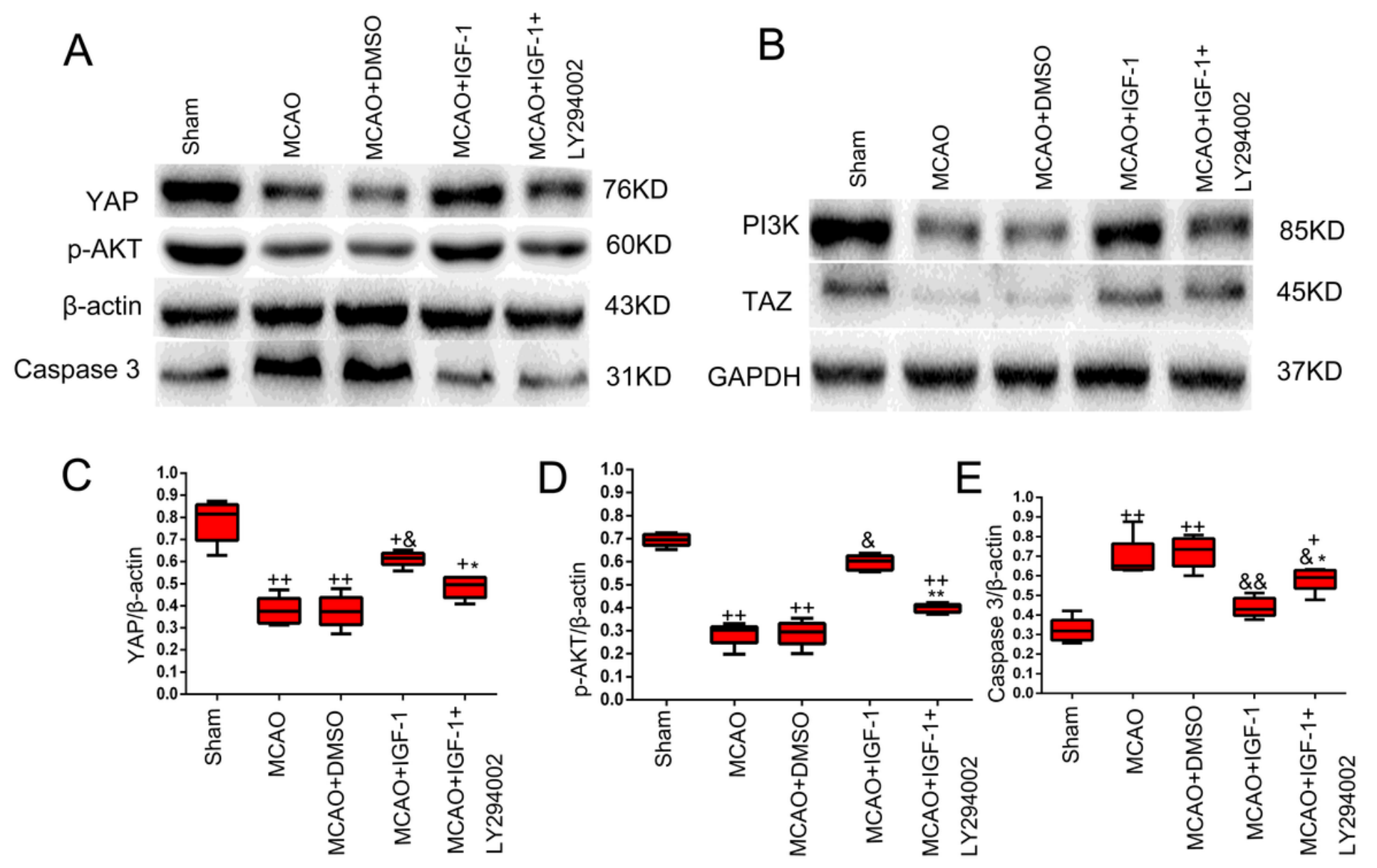

$\mathrm{F}$

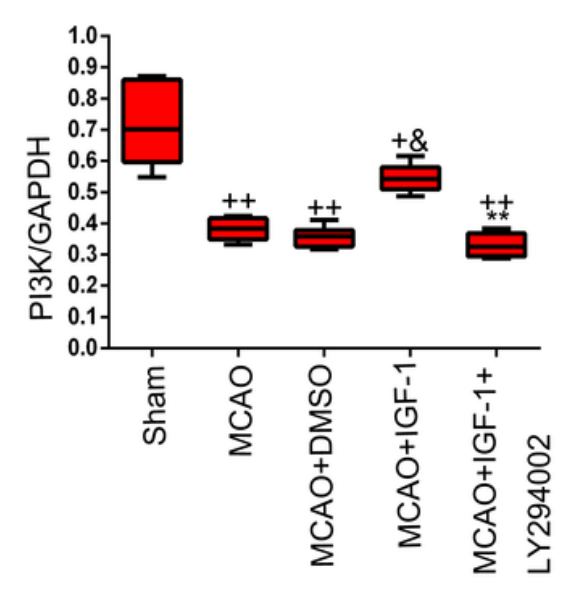

G

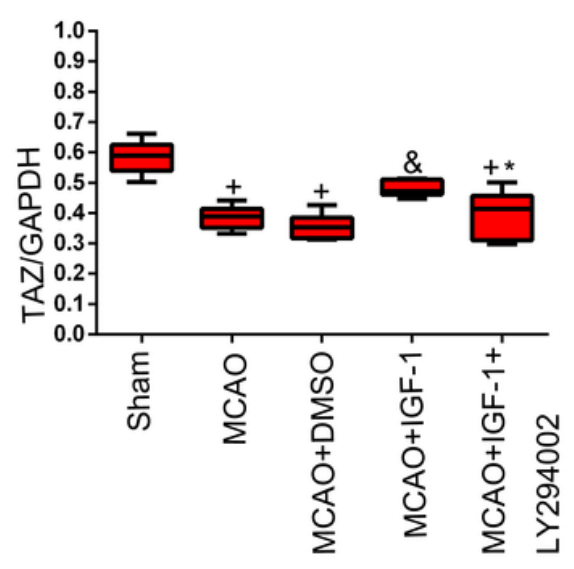

Figure 9

IGF-1 promoted YAP/TAZ and PI3K/p-AKT expression, and down-regulated Caspase 3 expression. (A) YAP, p-AKT and Caspase 3 in the different groups were detected using western blot. $\beta$-actin was used as 
loading control ( $\mathrm{n}=5$ rats per group). (B) PI3K and TAZ in the different groups were detected using western blot. GAPDH was used as loading control ( $n=5$ rats per group). (C-G) Quantified levels of $\mathrm{YAP} / \mathrm{TAZ}, \mathrm{PI} 3 \mathrm{~K} / \mathrm{p}-\mathrm{AKT}$ and Caspase 3 in the different groups. $+\mathrm{p}<0.05,++\mathrm{p}<0.01 \mathrm{vs}$. the Sham group; $\& p<0.05, \& \& p<0.01$ vs. the MCAO group; ${ }^{*}<0.05,{ }^{\star *} p<0.01$ vs. the MCAO+IGF-1 group. 